Chen, et al., 2020

\title{
Stretch and Twist of HEAT Repeats Leads to Activation of DNA-PK Kinase
}

Xuemin Chen ${ }^{1}$, Xiang $\mathrm{Xu}^{1, *, \&}$, Yun Chen ${ }^{1, *, \#,}$, Joyce C. Cheung ${ }^{1, \%}$, Huaibin Wang ${ }^{2}$, Jiansen Jiang ${ }^{3}$, Natalia de Val ${ }^{4}$, Tara Fox ${ }^{4}$, Martin Gellert ${ }^{1}$ and Wei Yang ${ }^{1}$

${ }^{1}$ Laboratory of Molecular Biology and ${ }^{2}$ Laboratory of Cell and Molecular Biology, NIDDK, and ${ }^{3}$ Laboratory of Membrane Proteins and Structural Biology, NHLBI, National Institutes of Health, Bethesda, MD 20892. 4 Cancer Research Technology Program Frederick National Laboratory for Cancer Research, Leidos Biomedical Research Inc., Frederick, MD 21701, USA.

* These authors contributed equally.

\& Current address: xuxiang14514@126.com

\# Current address: yun.chen@beigene.com

\% Current address: jcycheung@gmail.com

Running title: $\quad$ Slinky-like HEAT-repeat Movement Leads to DNA-PK Activation

Keyword: $\quad$ DNA-PKcs, Ku70, Ku80, PIKKs, DNA-end binding

Correspondence: Wei Yang (weiy@niddk.nih.gov)

Martin Gellert (martinge@niddk.nih.gov) 
Chen, et al., 2020

\begin{abstract}
Phosphatidylinositol 3-kinase-related kinases (PIKKs) are composed of conserved FAT and kinase domains (FATKIN) along with varied solenoid structures made of HEAT repeats. These kinases are activated in response to cellular stress signals, but the mechanisms governing activation and regulation remain unresolved. For DNA-dependent protein kinase (DNA-PK), all existing structures represent inactive states with resolution limited to $4.3 \AA$ at best. Here we report the cryoEM structures of DNA-PKcs (catalytic subunit) bound to a DNA end, or complexed with Ku70/80 and DNA, in both inactive and activated forms at resolutions of $3.7 \AA$ overall, and $3.2 \AA$ for FATKIN. These structures reveal the sequential transition of DNA-PK from inactive to activated forms. Most notably, activation of the kinase involves previously unknown stretching and twisting within individual solenoid segments and coordinated shifts of neighboring segments in opposite directions. This unprecedented structural plasticity of helical repeats may be a general feature of HEAT-repeat proteins.
\end{abstract}


Chen, et al., 2020

\section{Introduction}

The DNA-dependent protein kinase (DNA-PK) is central to the process of nonhomologous end joining (NHEJ) in both programmed gene arrangement and after unwanted DNA breakage (Davis et al., 2014). DNA-PK consists of a large catalytic subunit, known as DNA-PKcs, and the Ku70/80 heterodimer (Ku70/80) (Gottlieb and Jackson, 1993; Lees-Miller et al., 1990). DNA-PKcs is a Ser/Thr kinase of over 4000 residues and a member of the PI3K-related kinase (PIKK) family, which also includes mTOR, ATM, ATR and SMG1 (Baretic and Williams, 2014; Hartley et al., 1995). PIKK kinases play key roles in regulation of responses to nutrient stress (mTOR), misfolded and non-functional RNAs (SMG1), DNA double-strand breaks (DNA-PKcs and ATM) or single-stranded DNA (ATR) (Blackford and Jackson, 2017; Langer et al., 2020; Yang et al., 2017). The kinase activity of DNA-PKcs is modestly stimulated by DNA but becomes fully activated only in the presence of both DNA and Ku70/80, which is known to bind DNA ends (Chan and Lees-Miller, 1996; Hammarsten and Chu, 1998; Mimori et al., 1986; West et al., 1998). When activated, DNA-PK can phosphorylate both itself (autophosphorylation) and other repair factors (Meek et al., 2008). DNA-PKcs and Ku70/80 have also been implicated in telomere maintenance, RNA and ribosome biogenesis and the innate immune response to foreign DNAs (Hande, 2004; Meek, 2020; Shao et al., 2020).

Structures of the DNA-bound DNA-PK holoenzyme as well as DNA-PKcs associated with the C-terminal region (CTR) of Ku80 have been reported at $6.6 \AA$ and 4.3-4.4 Å resolution, respectively (Baretic et al., 2019; Sharif et al., 2017; Sibanda et al., 
2017; Yin et al., 2017). The first 3700 residues of DNA-PKcs are folded into $65 \alpha$-helical HEAT repeats with a single $\beta$ hairpin and arranged as an open N-HEAT ( $\mathrm{N}$ for $\mathrm{N}$ terminus) and a closed M-HEAT (M for middle) solenoid ring (Yin et al., 2017), which are nearly concentric, followed by the C-shaped FAT domain (Fig. 1a). The kinase domain at the $\mathrm{C}$ terminus occupies the hole in the FAT domain, and the two together, referred to as FATKIN (Baretic and Williams, 2014), form the "head" atop the double-ring "body". The helical repeats are folded sequentially, going in opposite directions in the consecutive $\mathrm{N}$ - and M-HEAT rings. These two rings are linked back-to-back at the neck between the head and body but are splayed apart on the opposite side (the bottom), where DNA and the Ku subunits bind (Yin et al., 2017). Upon DNA and Ku binding, the first half of N-HEAT undergoes a rotational movement and converts the half-circle $\mathrm{N}$ HEAT to a nearly closed ring (Yin et al., 2017) (Fig. 1, Video 1). The shape of DNA-PK and locations of domains are clearly defined, but at the resolution of $4.3-6.6 \AA$, functional interfaces between protein domains and between protein and DNA are less certain.

Multiple structures of other PIKK kinases complexed with accessory subunits, activation cofactors, ATP analogs, and even a substrate peptide have been reported, representing either active mTOR and SMG1 (Langer et al., 2020; Yang et al., 2017) or inhibited ATM and ATR (Jansma et al., 2020; Williams et al., 2020). In all cases the role of the HEAT-repeat structures, which is 5 to 9 -fold larger than the kinase domain, remains unclear. Among PIKKs, DNA-PK is unique in its autonomous full activation by a short DNA duplex and auto-phosphorylation of its three subunits. 
Here we report eight cryoEM structures of DNA-PKcs complexed with DNA or with DNA and Ku70/80 at $3.2-4.3$ A resolutions. These structures reveal the previously unknown function of DNA-end binding by DNA-PKcs, and in addition, an activated state of DNA-PK in association with the DNA end. Binding of Ku and a DNA end drive the intrinsic plasticity of DNA-PKcs toward kinase activation with coordinated stretching and twisting of helical repeats. The Slinky-like movement observed with DNA-PKcs may be general among HEAT-repeat proteins.

\section{Results}

\section{cryoEM structures of DNA-PK}

DNA-PKcs purified from HeLa cell nuclear extract was mixed with Ku70/80 and a 40 bp DNA that contained identical blunt ends with two internal nicks (Fig. 1b). Formation of the complete DNA-PK complex was confirmed by size-exclusion chromatography. CryoEM analysis of DNA-PK (see Materials and Methods) revealed three major species of protein-DNA complexes: DNA-PKcs-DNA, and inactive and activated holo-DNA-PK complexes (with Ku), two of which had more than one variant (Figs. 1c, S1). The FATKIN domains of the inactive and activated DNA-PK complexes were locally refined to 3.2 - 3.3 Å resolution (Table S1).

The two DNA-PKcs-DNA complex structures (I and II) at $4.3 \AA$ resolution showed that DNA-PKcs alone can bind a DNA broken end and contact 15 bp. Complex I represented an initial DNA-binding state with DNA at the periphery of DNA-PKcs, whose protein structure was similar to a DNA-free DNA-PKcs (Sharif et al., 2017) (Fig. S2a), which was isolated from a sample containing DNA and Ku by cryoEM (Sharif et al., 2017). 
The structure of complex II showed that DNA and the associated N-HEAT region moved into the DNA-binding groove between $\mathrm{N}$ - and M-HEAT. The next three complexes (III to V) had DNA-bound to DNA-PK at 4.1 to $3.9 \AA$ resolutions, with the Ku component increasingly resolved extending from the core (III-IV) to Ku80-CTR (V) (Fig. 1c). Structural differences between complexes III and IV probably reflected the dynamic flexibility of DNA-bound DNA-PK. With Ku80-CTR firmly docked, the structure of complex V became more stable. Interactions between DNA-PKcs and DNA were similar to those in complexes I and II, but specific contacts to the DNA end were formed in complexes III-V. While the protein and DNA components in complexes III-V and the previously reported DNA-PK structure (PDB: 5Y3R)(Yin et al., 2017) were similar, our complexes appeared to be expanded (Fig. S2b) and revealed specific binding of the DNA end and KU80-CTR by DNA-PKcs.

The activated DNA-PK complex (VI, at $3.7 \AA$ resolution) exhibited extensive conformational changes. Compared to inactive complexes, the FATKIN head was raised, and the $\mathrm{N}$ - and $\mathrm{C}$-lobes of kinase domain became open (Fig. 1C). Moreover, the PIKK regulatory domain (PRD, aa 4009-4039), which is partially disordered in mTOR and SMG1 (Langer et al., 2020; Yang et al., 2017), and closed in ATM, ATR (Jansma et al., 2020; Williams et al., 2020), and in all other DNA-PKcs and DNA-PK complexes, rotated $115^{\circ}$ to expose the substrate binding groove. Complex VI also revealed that the activated DNA-PKcs has a potential binding site for inositol hexaphosphate (IP6), which has been shown to activate DNA-PK and NHEJ (Hanakahi et al., 2000). An IP6-binding site was first found in SMG1 and was predicted to be general among PIKKs, but had been absent 
in the existing DNA-PKcs structures (Gat et al., 2019), all of which represent inactive states.

\section{Structural comparison with apo DNA-PKcs}

As our cryoEM density maps were of moderate resolution, to improve the structures and also for comparison, we took advantage of methionine locations well defined by selenium replacement of sulfur in the crystal structure of DNA-PKcs (PDB: 5LUQ, $4.3 \AA$ ) (Sibanda et al., 2017). In the process of building cryoEM models, we were able to re-refine the DNA-PKcs crystal structure (Table S2) (Fig. S2c), resulting in reduced $\mathrm{R}$ and $\mathrm{R}_{\text {free }}$ (each by $\sim 10 \%$ ), reduced clash score and $\mathrm{B}$ values, and increased favorable Ramachandran distributions (Table S2). Re-assignment of secondary structures in DNA-PKcs was necessary to optimize this refinement (Fig. S3). The largest change was a 130-aa shift in the middle of the M-HEAT ring and involved over 200 residues in the crystal structure of DNA-PKcs (PDB: 5LUQ) and the cryoEM structure of DNA-bound DNA-PK (PDB: 5Y3R).

Domain and subdomain boundaries were determined by comparison of apo, inactive, and activated DNA-PKcs structures using Difference Distance Matrix Plot (DDMP) (Richards and Kundrot, 1988) (Fig. S4). According to established conventions (Sibanda et al., 2017; Yin et al., 2017), the three regions of DNA-PKcs are: N-HEAT (1872), M-HEAT (890-2580), and FATKIN (2800-4128) (Fig. 2a-c). N-HEAT is broken into two segments ( $\mathrm{NH} 1$ and $\mathrm{NH} 2$ ), each containing 8 helical repeats. $\mathrm{NH} 1$ (aa 1-380) binds 14 bp of DNA and interacts with $\mathrm{Ku}$, while $\mathrm{NH} 2$ (aa 381-872) caps the DNA end and directly contacts M-HEAT and FATKIN (Fig. 2a). M-HEAT contains 32 helical repeats and 
assumes a heart shape in three segments (Fig. 2b). MH1 (aa 890-1092) forms domain connections at the neck; $\mathrm{MH} 2$ (aa 1093-1575) contacts $\mathrm{NH} 2$ and the N lobe of kinase at right angles; the large MH3 (aa 1576-2580) binds Ku and DNA and closes the M-HEAT ring (Fig. 2b). Based on DDMP analyses, M-HEAT, particularly $\mathrm{MH}$, is changed least among DNA-PKcs structures (Fig. S4).

The FAT domain starts at residue 2800, but the first segment FR1 (aa 2800-2944) actually moves with MH3 (Fig. 2c). The next segment FR2 (aa 2950-3199) contains nonrepeating helices and interacts extensively with $\mathrm{N}$ - and M-HEAT at the neck, where the C lobe of kinase is also docked. The last section FR4 (3407-3564) interacts with the FRB (FKBP12-rapamycin-binding) domain and the N lobe of kinase, but FR3 (aa 3226 3394) between FR2 and FR4 has few interactions with the rest of DNA-PKcs. The conserved kinase domain (aa 3714 - 4128) (Fig. 2d) includes FATC (aa 4000-4128) as an intrinsic part of the C-lobe, as noted previously (Yang et al., 2013).

\section{DNA binding by DNA-PKcs}

Previously, Ku80 was implicated in direct DNA-end binding by DNA-PK (Sibanda et al., 2017; Yin et al., 2017). In the better resolved cryoEM structures and crystal structure (Table S1, S2), the helices near the DNA end initially assigned to Ku80 were shown to belong to MH3 (as A7 in PQR, see explanation below) (Fig. 2b). Only DNAPKcs has direct contacts with the DNA end and the proximal $15 \mathrm{bp}$. This observation is supported by observations that DNA-PKcs by itself has weak DNA-end binding activity (Cary et al., 1997; West et al., 1998) and that its kinase activity is slightly activated by DNA in the absence of Ku (Chan and Lees-Miller, 1996; Hammarsten and Chu, 1998). 
In the two DNA-PKcs-DNA structures (I and II), only 24 bp of DNA are ordered (Fig. 3a). The $5^{\text {th }}$ to $15^{\text {th }}$ bp of DNA are bound by five helical repeats ( $3^{\text {rd }}$ to $7^{\text {th }}$, aa $161-331$ ) of $\mathrm{NH} 1$ around the minor groove (Fig. 3b). Meanwhile the DNA end is contacted by the $9^{\text {th }}$ to $11^{\text {th }}$ helical repeats (aa 401-524) of $\mathrm{NH} 2$ (Fig. 3c). In converting from complex I to II, the DNA and $\mathrm{NH} 1$ move together by a rotation of $20^{\circ}$, which leads to a $10-\AA \AA$ shift from their being at the periphery of the M-HEAT ring to its center (Movie 2). As the DNA moves to the center, a pair of $\alpha$ helices (A1 and A2) (Fig. S3) extends from the $16^{\text {th }}$ repeat of $\mathrm{N}$ HEAT toward it, with one side contacting DNA across the major groove and the other side contacting the $1^{\text {st }}$ and $2^{\text {nd }}$ repeats of N-HEAT (Fig. 2a, 3b).

Upon Ku binding and thus holo-DNA-PK formation (complexes III to $\mathrm{VI}$ ), 37 of the $40 \mathrm{bp}$ of DNA became stably ordered in these structures, as Ku bound DNA next to DNAPKcs. In the transition from without (I-II) to with $\mathrm{Ku}(\mathrm{III}-\mathrm{V})$, the entire DNA and the associated N-HEAT moved toward M-HEAT and also toward the outside of the M-HEAT ring by a $12^{\circ}$ rotation and $8 \AA$ translation, as if an arrow (DNA) were pulled (by Ku) further from the bow (M-HEAT) (Movie 3). In complexes III-V, the last helical repeat of $\mathrm{NH} 1\left(8^{\text {th }}\right)$ finally makes contact with the DNA end, and in it N356, K357, and the positive helical dipole coordinate the $2^{\text {nd }}$ and $3^{\text {rd }}$ phosphates from the DNA $5^{\prime}$ end (Fig. $3 c$ ). The $5^{\prime}$ end, however, appears to be free. In contrast, the DNA $3^{\prime}-\mathrm{OH}$ is covered by W519, and the adjacent phosphates are bound by K518 and K520 (Fig. 3c). The asymmetric binding of $5^{\prime}$ and $3^{\prime}$ ends suggests that DNA-PKcs can easily accommodate a $5^{\prime}$ overhang (Fig. $3 c$ ). For the strand to continue as in DNA with a $3^{\prime}$ overhang or hairpin end, it has to bend away from the protein cap made of K518-K520. 
The interactions of DNA with DNA-PKcs become more extended when the holoDNA-PK complex shifts toward the activated state. As the groove between the $\mathrm{N}$ - and $\mathrm{M}$ HEAT rings that sandwich the DNA becomes narrower, the interface between DNA-PKcs and DNA increases from $918 \AA^{2}$ in complex $\mathrm{V}$ to $1036 \AA^{2}$ in complex VI. Previously disordered loops (aa 801-817 and 839-846 of the $16^{\text {th }}$ helical repeat in N-HEAT) become ordered and contact M-HEAT at aa $2430-2511$ (Fig. 3b). In addition to the protein-DNA interactions observed in complexes I-V, MH3 directly contacts the $4^{\text {th }}-5^{\text {th }}$ bp via $\mathrm{K} 2227$, and the $9^{\text {th }}-10^{\text {th }}$ bp via R2311 in complex VI (Fig. 3d). As the DNA is pushed against $\mathrm{MH} 3$ inside the HEAT rings, it is bent by $\sim 20^{\circ}$ away from M-HEAT and toward N-HEAT at the interface between DNA-PKcs and Ku.

\section{Ku stabilizes DNA-PKcs-DNA interaction}

$\mathrm{Ku}$ is situated outside of DNA-PKcs and contacts the NH1 of N-HEAT and the MH3 of M-HEAT on either side of the DNA binding groove (Fig. 4a). Ku in the DNA-PK holoenzyme had essentially the same structure as in Ku-DNA complexes (Nemoz et al., 2018; Walker et al., 2001). When the Ku80 structures with and without DNA-PKcs were superimposed, the RMSD was $1.5 \AA$ A over 500 pairs of $\mathrm{C} \alpha$ atoms. The amino-terminal $\alpha / \beta$ domain of Ku70, which barely contacts DNA in the Ku-DNA complexes, binds MH3 (aa $2350-2420)$ and DNA ( $14^{\text {th }}-16^{\text {th }}$ bp) tightly in complexes III-VI (Fig. 4b) by a rotation of $28^{\circ}$ relative to the rest of Ku protein. The broad Ku70/80 base (composed of $\alpha / \beta$ and $\beta$ barrel domains) becomes an extension of the MH3 of DNA-PKcs in binding DNA, protecting $15 \mathrm{bp}\left(14^{\text {th }}\right.$ to $\left.28^{\text {th }}\right)$ (Fig. 3d, 4a-b). While maintaining similar DNA interactions as $\mathrm{Ku}$ alone, the bridges of Ku70/80 contact the $3^{\text {rd }}$ to $5^{\text {th }}$ helical repeats of $\mathrm{NH} 1$ on the 
Chen, et al., 2020

side opposite to the DNA (Fig. 4c). Therefore, Ku stabilizes the DNA-PKcs-DNA association by not only extending DNA binding, but also by fastening N-HEAT of DNAPKcs onto DNA.

While the first 30 residues and the C-terminal SAP domain of Ku70 (aa 535-609) remained undetectable as in other Ku structures, Ku80-CTR (aa 542-732) becomes stable in complex V and VI structures (Fig. 1c). The folded domain in CTR (aa 595-706) is docked onto MH3 (aa 1700-1830), $65 \AA$ away from the bulk of Ku, by a small interface of both hydrophobic and polar nature. In addition, a short helix of Ku80 (aa 548 - 555) is tucked between the $5^{\text {th }}$ and $6^{\text {th }}$ helical repeats of $\mathrm{NH} 1$ adjacent to the bridge and pillar of Ku70 (Fig. 4c). Selenium labeling of M731 (Sibanda et al., 2017) led to unequivocal identification of the last helix of Ku80 (aa 718-732), which is the only part of Ku80 present in the crystal structure of DNA-PKcs (Sibanda et al., 2017) (Fig. S2c-d). The last Ku80 helix is docked $20 \AA$ away at aa 1910-1970 of MH3, resulting in Ku contacting all four corners of the DNA-PKcs DNA-end binding groove in complexes V and VI (Fig. 4a).

\section{Phosphorylation sites in DNA-PKcs}

Residues 2581-2783 include the well-known auto-phosphorylation sites of DNAPKcs, the ABCDE cluster (aa 2609-2647) (Ding et al., 2003; Neal et al., 2016). This 220aa stretch was partially built in the apo crystal structure (PDB: 5LUQ and 7K17) inside the M-HEAT ring extending toward the center, where DNA would bind. In all six cryoEM structures, a relatively featureless density approximating the volume of the missing 200 residues was found outside of the M-HEAT ring and adjacent to the substrate binding groove of the kinase domain. We suspect that this density represents the mobile ABCDE 
region (Fig. S5) and speculate that the displacement of $A B C D E$ from inside to outside the M-HEAT ring is correlated with DNA-end binding. Being near the kinase active site in the complexes with DNA, ABCDE may be phosphorylated in cis and facilitate downstream events in NHEJ (Crowe et al., 2020).

The second phosphorylation cluster (aa 2023-2056), known as PQR (Cui et al., 2005; Neal et al., 2016), is most peculiar. Among HEAT repeats of DNA-PKcs, PQR is the only part that does not follow a sequential folding pattern (Fig. 2b). As compounded by disordered linkers between helices, PQR caused the largest mis-tracing in the crystal structure (Sibanda et al., 2017). Instead of being near helix A7 (aa 2000- 2018) and the $37^{\text {th }}$ helical repeat (Fig. S3), helix A8 (aa 2037-2045) of PQR is located $55 \AA$ away and adjacent to the $32^{\text {nd }}$ and $33^{\text {rd }}$ helical repeats (aa 1575-1640) (Fig. 2b). The linker between A7 and A8 contains only 20 residues, which is a small number for the $55-60 \AA$ separating the two. Interestingly, helices A7 and A8 co-exist in the crystal structure with A7 shifted 5 $\AA$ towards $\mathrm{A} 8$, but in each of our six cryoEM structures, either A7 or A8 is found, but not both. Helix A8 is dominant in four out of the five inactive complexes, whereas in the activated DNA-PK complex (VI) helix A7 is found in $75 \%$ of the population. Although disordered, the linkers inside of the M-HEAT ring have to cross paths with the DNA end and parts of N-HEAT. Although phosphorylation sites in the PQR cluster remain disordered, their locations suggest trans phosphorylation (as it is $90 \AA$ away from the cis kinase domain) and potential influence on binding of DNA ends and repair partners inside the M-HEAT ring.

Other phosphorylation sites of DNA-PKcs (except for S3205) are in ordered 
regions, and their functions can be rationalized. $S 72$ is adjacent to the bridges of Ku; its phosphorylation would interfere with interactions of DNA-PKcs and Ku and consequently destabilize DNA-PKcs-DNA binding. Indeed, phosphorylation of S72 has been reported to inactivate the kinase (Neal et al., 2011). T946 and S1003, whose phosphorylation has no effect on the kinase activity but inhibits the NHEJ pathway, may have additive effects with the neighboring ABCDE cluster in repair partner choices (Neal et al., 2011; Neal et al., 2016). T3950, which belongs to the activation loop of the kinase (Douglas et al., 2007), is buried in the available structures, and has to undergo conformational changes to be phosphorylated and modulate DNA-PK function.

\section{Activation of the kinase}

In the activated state (complex $\mathrm{VI}$ ), the position of FATKIN relative to $\mathrm{N}$ - and $\mathrm{M}$ HEAT and its internal structure have changed dramatically (Movie 4) (Fig. 5a). In contrast, among complexes I to V, FATKIN moves little and only as a rigid body (Fig. S4, DDMP). The telltale sign of the activated state was the rotation of the PRD loop by $115^{\circ}$ and opening of the binding groove for substrate (Fig. 2d). The positively charged putative IP6binding site is nearby, wedged between FAT and kinase domains (Fig. 5b). Unlike mTOR and SMG1, when ATP or non-hydrolyzable ATP analogs were added to our sample, the DNA-PK complexes became highly heterogeneous and structural characterization was not possible. In the absence of ATP or ATP analogs, however, both the inactive and activated forms of DNA-PK were present in our samples.

We asked how DNA and Ku activate the kinase activity of DNA-PKcs and what kinds of structural changes in the HEAT repeat rings are associated with this activation. 
Conformational changes from complex $\mathrm{V}$ to $\mathrm{VI}$ appear to emanate in the neck, where $\mathrm{N}$ and M-HEAT, FAT and the C-lobe of the kinase converge. As shown in the animation (Movie 4), the NH1 and FR2 segments move toward each other to close the N-HEAT ring, and the entire ring including FR2 moves downward and enters the M-HEAT ring (Fig. 5c). Meanwhile, helix A4, linking N-HEAT to M-HEAT (Fig. S3), is squeezed out of the neck and rises up $4 \AA$ toward the kinase. Adjacent to helix A4, the C-lobe of kinase rises as well, together with FAT except for the FR2 segment, giving the impression of a raised FATKIN head (Fig. 5a). As the C-lobe is at the C-terminus of DNA-PKcs, but physically adjacent to FR2, the upward movement of kinase and downward movement of FR2 lead to unusual changes of every portion between them (Movies 4). As it is pulled in opposite directions, FR3 changes the twists between its helical repeats, and FR4 expands by increasing the distance between helical repeats (Fig. 5d). The solenoid made of FR3 and FR4 becomes more extended and more twisted in the activated state (Movie 5). As these changes happen, the PRD loop pops open. The importance of FR2 in kinase activation is supported by the observation that phosphorylation of $\mathrm{S} 56$ in $\mathrm{NH} 1$, which interfaces with FR2 in the activated state (Fig. 5c), causes kinase inactivation (Neal et al., 2011).

The dramatic changes in FATKIN are supported by changes in the two HEAT rings. As the N-HEAT ring enters, the M-HEAT ring expands (Movie 5), again by changing the distances and twisting angles between helical repeats. In the activated state, the $\mathrm{N}$ and C lobes of kinase also rotate away from each other, making room for substrate binding. This bidirectional movement appears to be correlated with the expansion of M-HEAT, which maintains interactions with the $\mathrm{N}$-lobe of kinase by changing contacting residues. 
DNA-PKcs alone is rather flexible, as evidenced in the differences between noncrystallographic symmetry mates (Sibanda et al., 2017) (Fig. S2d). But the intrinsic dynamics of DNA-PKcs are insufficient to re-arrange and activate the kinase. Binding of a DNA end leads to the re-organization of N-HEAT and brings NH1 and FR2 much closer than in apo structures, as shown in complex II. The closeness of NH1 and FR2 may explain the low kinase activity of DNA-PKcs in the presence of DNA (Chan and LeesMiller, 1996). Binding of Ku70 and the entirety of Ku80 stabilizes the DNA-PKcs-DNA complex and shifts the ensemble of DNA-PKcs structures towards kinase activation.

\section{Discussion}

The extensive global changes of DNA-PKcs that culminate to its activated state are results of local movements of helical repeats. Such movements within individual solenoids may be a common theme among HEAT-repeat proteins. For example, the fantastic shape changes of nuclear transport karyopherins exhibit local stretch and twist of helical repeats among large rigid-body conformational changes (Conti et al., 2006; Cook and Conti, 2010). Among PIKKs, binding of RHEB GTPase to mTORC1 also induces stretch and twist of helical repeats locally (Yang et al., 2017). In the case of DNA$\mathrm{PK}$, the extensive ensemble motions are supported by the binding of Ku and a DNA end. Although $\mathrm{Ku}$ is well known for its DNA end-binding activity, the cryoEM DNA-PK structures reported here reveal that Ku does not specifically bind DNA ends. The apparent DNA-end recognition is probably due to Ku's closed topology, which requires it to bind DNA only via an open end by threading. Once on DNA, Ku has no direct contact with either the $3^{\prime}$ or $5^{\prime}$ end and can slide along following the DNA contour. This closed topology 
requires loading $\mathrm{Ku}$ first onto a broken DNA end in forming a functional DNA-PK holoenzyme. The association of Ku80's last helix and DNA-PKcs is rather hydrophobic and DNA independent (Sibanda et al., 2017) and may enable the two to find DNA ends together. For DNA ends to be repaired, DNA-PKcs must yield the DNA ends to nuclease, DNA polymerase, other repair factors, and ligase IV. In the process, DNA-PKcs may slide inward along DNA with $\mathrm{Ku}$. As shown in complexes $\mathrm{V}$ and $\mathrm{VI}$, the full engagement of $\mathrm{Ku}$ with DNA and DNA-PKcs establishes a solid base of DNA-PK (Fig. 4a), on which extensive stretch and twist of HEAT repeats can take place and lead to the kinase activation. After seeing the extended and multifaceted stretch and twist of HEAT repeats in DNA-PK, we speculate that Slinky-like structural plasticity may be general among the vast number of HEAT proteins, PIKKs, karyopherins, condensins and cohesins alike. The trick for us is to catch them in action. 
Chen, et al., 2020

\section{STAR Methods}

\section{Protein and DNA purification}

DNA-PKcs was purified from HeLa cells (purchased from National Cell Culture Center, Minneapolis, MN) using a protocol we developed in 2009 based on a published method (Chan and Lees-Miller, 1996; Williams et al., 2008). The nuclear extracts were prepared according to the standard protocol (Abmayr et al., 2006) and then fractionated with $60 \%$ saturated ammonium sulfate. The precipitate was dissolved in DEAE loading buffer (50 $\mathrm{mM}$ HEPES pH 7.9, $75 \mathrm{mM} \mathrm{KCl}, 5 \%$ glycerol, $1 \mathrm{mM}$ EDTA and $1 \mathrm{mM}$ DTT) and clarified before loading onto a 200mL DEAE Sepharose FF column (GE Healthcare) preequilibrated with the loading buffer. DNA-PKcs fractions eluted from the DEAE column (in a gradient of $75-300 \mathrm{mM} \mathrm{KCl}$ ) were pooled and diluted to a salt concentration of $150 \mathrm{mM}$ $\mathrm{KCl}$ before loading onto a HiTrap Heparin HP column (GE Healthcare). A linear gradient of $150-500 \mathrm{mM} \mathrm{KCl}$ was applied to elute the protein, and the DNA-PKcs fractions were further purified using a Mono Q 10/100 GL anion exchange column (GE Healthcare) and eluted with a linear gradient of 150 to $350 \mathrm{mM} \mathrm{KCl}$. The final purification step was on a Superose 6 10/300 GL size exclusion column (GE Healthcare) pre-equilibrated with 50 $\mathrm{mM}$ HEPES pH 7.9, $300 \mathrm{mM} \mathrm{KCl}$, and $1 \mathrm{mM}$ DTT. The purified DNA-PKcs protein was buffer exchanged to $50 \mathrm{mM}$ HEPES $\mathrm{pH} 7.9,300 \mathrm{mM} \mathrm{KCl}, 50 \%$ glycerol and $1 \mathrm{mM}$ DTT, flash frozen in liquid nitrogen and stored at $-80^{\circ} \mathrm{C}$. All protein purification steps (including Ku purification described below) were carried out at $4^{\circ} \mathrm{C}$, and protease inhibitors $(100 \mathrm{mM}$ PMSF, $1 \mathrm{mM}$ pepstatin, $10 \mathrm{mg} / \mathrm{mL}$ aprotinin, $5 \mathrm{mg} / \mathrm{mL}$ leupeptin) were added to the buffer before each step of chromatography.

Ku70/80 protein was over-expressed and purified from HEK293T cells. Genes encoding full length Ku70 and Ku80 were cloned into pLEXm vector separately, and a His6-MBP tag and PreScission cleavage site were added to the N-terminus of Ku70 (Kim et al., 2015). HEK293T cells were pelleted 3 days after transfection and resuspended in 1/10 culture volume of lysis buffer $(20 \mathrm{mM}$ HEPES pH $7.9,0.5 \mathrm{M} \mathrm{KCl}, 5 \%$ glycerol, $0.5 \mathrm{mM}$ EDTA, $1 \mathrm{mM}$ DTT and 1 tablet of Roche cocktail protease inhibitors). After sonication and centrifugation at $35,000 \mathrm{~g}$ for $1 \mathrm{~h}$, the clear supernatant was applied to an amylose affinity column. After thorough wash, Ku protein was eluted in $20 \mathrm{mM}$ HEPES pH 7.9, $0.5 \mathrm{M} \mathrm{KCl}$, $5 \%$ glycerol, $40 \mathrm{mM}$ maltose, $0.5 \mathrm{mM}$ EDTA and $1 \mathrm{mM}$ DTT. After removal of the $\mathrm{N}$ terminal His6-MBP tag by PreScission Protease, the protein was loaded onto a Mono $Q$ $10 / 100 \mathrm{GL}$ anion exchange column (GE Healthcare) in $20 \mathrm{mM}$ HEPES pH7.9, $100 \mathrm{mM}$ $\mathrm{KCl}, 1 \mathrm{mM}$ DTT, $0.5 \mathrm{mM}$ EDTA. Ku protein was eluted in a linear gradient of $100-500 \mathrm{mM}$ $\mathrm{KCl}$. The purified Ku70/80 fraction was buffer-exchanged into $20 \mathrm{mM}$ HEPES pH7.9, $150 \mathrm{mM} \mathrm{KCl}, 50 \%$ glycerol, $1 \mathrm{mM}$ EDTA, $1 \mathrm{mM}$ DTT, flash frozen in liquid nitrogen and stored at $-80^{\circ} \mathrm{C}$.

DNA oligos of 24 nt (5'-GCATGCTCTACTGCTTCGATATCG-3') and 16 nt (5'AAGCAGTAGAGCATGC-3') were purchased from IDT (Integrated DNA Technologies, Coralville, IA) and purified using an 8-15\% TBE-urea PAGE gel in small gel cassettes (Life Technologies). The oligonucleotides extracted from gel were loaded onto a Glen Gel-Pak column (Glen Research) and eluted with deionized $\mathrm{H}_{2} \mathrm{O}$. These oligos were 
annealed in a buffer containing $20 \mathrm{mM}$ Tris- $\mathrm{HCl}(\mathrm{pH} 8.0), 50 \mathrm{mM} \mathrm{NaCl}$ and $0.5 \mathrm{mM}$ EDTA in a Thermocycler to form a 40 bp DNA with identical blunt ends and two internal nicks (Fig. 1b). Such self-complementary DNA was initially designed as a cheap and easy way to make symmetric DNA of various length for co-crystallization with DNA-PK.

\section{Sample preparation and cryo-EM data collection}

To assemble DNA-PK holoenzyme, purified DNA-PKcs, Ku70/80 and 40 bp DNA were mixed at the molar ratio of 1:1.2:1.2 in $50 \mathrm{mM}$ HEPES pH 7.9, $100 \mathrm{mM} \mathrm{KCl}$ and $1 \mathrm{mM}$ DTT, and incubated at $4^{\circ} \mathrm{C}$ for $15 \mathrm{~min}$. The mixture was purified over a Superose $610 / 300 \mathrm{GL}$ column (GE Healthcare) pre-equilibrated with $50 \mathrm{mM}$ HEPES 7.9, $100 \mathrm{mM} \mathrm{KCl,} 1 \mathrm{mM}$ DTT. Protein and DNA components of the holoenzyme were confirmed by SDS and TBE-urea PAGE gels. Fractions containing DNA-PK holoenzyme were pooled and concentrated to $0.5 \mathrm{mg} / \mathrm{ml}$ for cryo-EM grids preparation.

The DNA-PK sample was loaded on either QUANTIFOIL R1.2/1.3 (Cu, 300 mesh) or Lacey grids (UC-A on holey 400 mesh $\mathrm{Cu}$ ), 3 ul per grid at $100 \%$ humidity and $4^{\circ} \mathrm{C}$ in a Vitrobot, blotted for $4 \mathrm{~s}$, and flash-frozen in liquid ethane. A total of 14742 micrographs from QUANTIFOIL grids were collected on the Titan Krios electron microscope operated at $300 \mathrm{kV}$ at the Multi-Institute Cryo-EM Facility (MICEF) of NIH in the super-resolution mode of $130 \mathrm{k}$ nominal magnification (calibrated pixel size of $0.54 \AA$, corresponding to $1.08 \AA$ at the sample level). An additional 7730 micrographs (4298 from QUANTIFOIL and 3432 from Lacey grids) were collected on a Titan Krios electron microscope operated at $300 \mathrm{kV}$ at the Frederick National Laboratory (Frederick, MD) in the counting mode with a nominal magnification of $175 \mathrm{~K}$ (calibrated pixel size of $0.86 \AA$ ). Lacey grids alleviated the preferred orientation problems manifested with QUANTIFOIL grids.

\section{Structure determination and model refinement}

The software MotionCor2 (Zheng, 2017) was used for drift correction, during which doseweighting was applied and the pixel size was binned to $1.16 \AA$ Apixel to merge all micrographs from the two microscopes. CTF (contrast transfer function) estimation was measured with the dose-unweighted micrographs using Gctf (Zhang, 2016). 2,945,665 particles were picked on dose-weighted micrographs using Gautomatch (developed by K. Zhang; https://www.mrc-Imb.cam.ac.uk/kzhang/Gautomatch) and extracted with RELION-3.0.8 (Fernandez-Leiro, 2017) using a box size of $352 \times 352$ pixels. An initial map was obtained with cryoSPARC (Punjani, 2017), and two-dimensional (2D) projections were generated for template-based particle picking. The re-picked 5,592,709 particles were subjected to 2D classifications in RELION-3.0.8. After excluding 3,258,196 bad particles, three-dimension (3D) classifications in RELION and cryoSPARC with and without alignment were applied to classify different conformations. The resulting good maps and the associated particles from 3D classifications were selected for further classifications and refinements according to the standard procedure (Fig. S1). All reported resolutions were determined based on the "gold standard" of the 0.143 Fourier shell correlation (FSC) criterion (Swint-Kruse, 2005). Local resolution was estimated using ResMap (Kucukelbir et al., 2014). For model building, we used the published 4.3- 
resolution apo DNA-PKcs structure (PDB: 5LUQ) (Sibanda et al., 2017) as the initial model to build cryo-EM structures of the $3.2 \AA$ inactive FATKIN and the $3.7 \AA$ DNA-PK complex VI, which then were used as the template for building Complexes I-V. We first fit the coordinates into the cryo-EM maps using Chimera (Pettersen et al., 2004), and then manually adjusted and rebuilt the models according to the cryo-EM density in COOT (Emsley, 2010). Real-space refinement in Phenix (Adams et al., 2010) was used to refine the models, and MolProbity (Chen et al., 2010) was used to validate the final model. The refinement statistics are summarized in Table S1. The detailed classifications and map qualities of the 8 structures reported in this manuscript are shown in a supplemental figure (Fig. S1).

For comparison and validation of our cryoEM structures of DNA-PK, we also rebuilt and refined the DNA-PKcs crystal structure (Sibanda et al., 2017) using the diffraction data deposited with the Protein Data Bank. Using our $3.7 \AA$ cryoEM DNA-PK complex VI structure as the initial model, we got a solution by Molecular Replacement and rebuilt the DNA-PKcs structure against the 2 Fo-Fc as well as Se anomalous maps in COOT. The model was iteratively refined using strategies of rigid body, group B factor, TLS parameters, XYZ (reciprocal-space and real-space), NCS application and secondary structure restraint in Phenix. MolProbity was used to validate the final model. A total of 7293 residues were built per asymmetric unit, which included 3629 and 3646 residues of DNA-PKcs in chain A and chain B, respectively, and the C-terminal residues 724-732 of Ku80 in chain $C$ and chain D. Rwork and $R_{\text {free }}$ of the re-refined structure of DNA-PKcs complexed with the C-terminal helix of Ku80 were 0.29 and 0.34 at $4.3 \AA$, respectively. The detailed refinement statistics are summarized in Table S2.

\section{Data Availability}

The structures and cryoEM maps have been deposited with EMDB and PDB with accession code of 7K19, 7K1B, 7K1J, 7K1K, 7K1N, 7K0Y, 7K11, 7K10 and EMD-22622, EMD-22623, EMD-22624, EMD-22625, EMD-22626, EMD-22618, EMD-22620, EMD22619. The re-refined crystal structure has been deposited in PDB with accession code of $7 \mathrm{~K} 17$. These data will be released immediately upon publication.

\section{Competing interests}

The authors declare no competing interest.

\section{Author contributions}

J.C.C. developed protocols for DNA-PKcs purification and complex assembly; X.X. and Y.C. improved DNA-PK complex preparation and collected cryoEM movies; X.C. and Y.C. processed cryoEM data, X.C. completed model building and structure analysis; H.W., N.d.V. and T.F. helped with cryoEM data collection, J.J. troubleshot cryoEM data collection and analysis, X.C., M.G. and W.Y. wrote the paper.

\section{Acknowledgements}

We are grateful to Drs. K. Meek and D. Leahy for critical reading of the manuscript. 
Chen, et al., 2020

\section{References}

Abmayr, S.M., Yao, T., Parmely, T., and Workman, J.L. (2006). Preparation of nuclear and cytoplasmic extracts from mammalian cells. Curr Protoc Mol Biol Chapter 12, Unit 12 11.

Adams, P.D., Afonine, P.V., Bunkoczi, G., Chen, V.B., Davis, I.W., Echols, N., Headd, J.J., Hung, L.W., Kapral, G.J., Grosse-Kunstleve, R.W., et al. (2010). PHENIX: a comprehensive Python-based system for macromolecular structure solution. Acta Crystallogr D Biol Crystallogr 66, 213-221.

Baretic, D., Maia de Oliveira, T., Niess, M., Wan, P., Pollard, H., Johnson, C.M., Truman, C., McCall, E., Fisher, D., Williams, R., et al. (2019). Structural insights into the critical DNA damage sensors DNA-PKcs, ATM and ATR. Prog Biophys Mol Biol 147, 4-16.

Baretic, D., and Williams, R.L. (2014). PIKKs--the solenoid nest where partners and kinases meet. Curr Opin Struct Biol 29, 134-142.

Blackford, A.N., and Jackson, S.P. (2017). ATM, ATR, and DNA-PK: The Trinity at the Heart of the DNA Damage Response. Mol Cell 66, 801-817.

Cary, R.B., Peterson, S.R., Wang, J., Bear, D.G., Bradbury, E.M., and Chen, D.J. (1997). DNA looping by Ku and the DNA-dependent protein kinase. Proc Natl Acad Sci U S A 94, 4267-4272.

Chan, D.W., and Lees-Miller, S.P. (1996). The DNA-dependent protein kinase is inactivated by autophosphorylation of the catalytic subunit. J Biol Chem 271, 8936-8941. Chen, V.B., Arendall, W.B., 3rd, Headd, J.J., Keedy, D.A., Immormino, R.M., Kapral, G.J., Murray, L.W., Richardson, J.S., and Richardson, D.C. (2010). MolProbity: all-atom structure validation for macromolecular crystallography. Acta Crystallogr D Biol Crystallogr 66, 12-21.

Conti, E., Muller, C.W., and Stewart, M. (2006). Karyopherin flexibility in nucleocytoplasmic transport. Curr Opin Struct Biol 16, 237-244.

Cook, A.G., and Conti, E. (2010). Nuclear export complexes in the frame. Curr Opin Struct Biol 20, 247-252.

Crowe, J.L., Wang, X.S., Shao, Z., Lee, B.J., Estes, V.M., and Zha, S. (2020). DNA-PKcs phosphorylation at the T2609 cluster alters the repair pathway choice during immunoglobulin class switch recombination. Proc Natl Acad Sci U S A.

Cui, X., Yu, Y., Gupta, S., Cho, Y.M., Lees-Miller, S.P., and Meek, K. (2005). Autophosphorylation of DNA-dependent protein kinase regulates DNA end processing and may also alter double-strand break repair pathway choice. Mol Cell Biol 25, 1084210852.

Davis, A.J., Chen, B.P., and Chen, D.J. (2014). DNA-PK: a dynamic enzyme in a versatile DSB repair pathway. DNA Repair (Amst) 17, 21-29.

Ding, Q., Reddy, Y.V., Wang, W., Woods, T., Douglas, P., Ramsden, D.A., Lees-Miller, S.P., and Meek, K. (2003). Autophosphorylation of the catalytic subunit of the DNAdependent protein kinase is required for efficient end processing during DNA doublestrand break repair. Mol Cell Biol 23, 5836-5848.

Douglas, P., Cui, X., Block, W.D., Yu, Y., Gupta, S., Ding, Q., Ye, R., Morrice, N., LeesMiller, S.P., and Meek, K. (2007). The DNA-dependent protein kinase catalytic subunit is 
phosphorylated in vivo on threonine 3950, a highly conserved amino acid in the protein kinase domain. Mol Cell Biol 27, 1581-1591.

Emsley, P., Lohkamp, B., Scott, W.G., and Cowtan, K. (2010). Features and development of Coot. Acta Crystallogr D Biol Crystallogr 66, 486-501.

Fernandez-Leiro, R., and Scheres, S.H.W. (2017). A pipeline approach to single-particle processing in RELION. Acta Crystallogr D Struct Biol 73, 496-502.

Gat, Y., Schuller, J.M., Lingaraju, M., Weyher, E., Bonneau, F., Strauss, M., Murray, P.J., and Conti, E. (2019). InsP6 binding to PIKK kinases revealed by the cryo-EM structure of an SMG1-SMG8-SMG9 complex. Nat Struct Mol Biol 26, 1089-1093.

Gottlieb, T.M., and Jackson, S.P. (1993). The DNA-dependent protein kinase: requirement for DNA ends and association with Ku antigen. Cell 72, 131-142.

Hammarsten, O., and Chu, G. (1998). DNA-dependent protein kinase: DNA binding and activation in the absence of Ku. Proc Natl Acad Sci U S A 95, 525-530.

Hanakahi, L.A., Bartlet-Jones, M., Chappell, C., Pappin, D., and West, S.C. (2000). Binding of inositol phosphate to DNA-PK and stimulation of double-strand break repair. Cell 102, 721-729.

Hande, M.P. (2004). DNA repair factors and telomere-chromosome integrity in mammalian cells. Cytogenet Genome Res 104, 116-122.

Hartley, K.O., Gell, D., Smith, G.C., Zhang, H., Divecha, N., Connelly, M.A., Admon, A., Lees-Miller, S.P., Anderson, C.W., and Jackson, S.P. (1995). DNA-dependent protein kinase catalytic subunit: a relative of phosphatidylinositol 3-kinase and the ataxia telangiectasia gene product. Cell 82, 849-856.

Jansma, M., Linke-Winnebeck, C., Eustermann, S., Lammens, K., Kostrewa, D., Stakyte, K., Litz, C., Kessler, B., and Hopfner, K.P. (2020). Near-Complete Structure and Model of Tel1ATM from Chaetomium thermophilum Reveals a Robust Autoinhibited ATP State. Structure 28, 83-95 e85.

Kim, M.S., Lapkouski, M., Yang, W., and Gellert, M. (2015). Crystal structure of the V(D)J recombinase RAG1-RAG2. Nature 518, 507-511.

Kucukelbir, A., Sigworth, F.J., and Tagare, H.D. (2014). Quantifying the local resolution of cryo-EM density maps. Nat Methods 11, 63-65.

Langer, L.M., Gat, Y., Bonneau, F., and Conti, E. (2020). Structure of substrate-bound SMG1-8-9 kinase complex reveals molecular basis for phosphorylation specificity. Elife 9.

Lees-Miller, S.P., Chen, Y.R., and Anderson, C.W. (1990). Human cells contain a DNAactivated protein kinase that phosphorylates simian virus $40 \mathrm{~T}$ antigen, mouse p53, and the human Ku autoantigen. Mol Cell Biol 10, 6472-6481.

Meek, K. (2020). An Antiviral DNA Response without the STING? Trends Immunol 41, 362-364.

Meek, K., Dang, V., and Lees-Miller, S.P. (2008). DNA-PK: the means to justify the ends? Adv Immunol 99, 33-58.

Mimori, T., Hardin, J.A., and Steitz, J.A. (1986). Characterization of the DNA-binding protein antigen Ku recognized by autoantibodies from patients with rheumatic disorders. J Biol Chem 261, 2274-2278. 
Neal, J.A., Dang, V., Douglas, P., Wold, M.S., Lees-Miller, S.P., and Meek, K. (2011). Inhibition of homologous recombination by DNA-dependent protein kinase requires kinase activity, is titratable, and is modulated by autophosphorylation. Mol Cell Biol 31, 1719-1733.

Neal, J.A., Xu, Y., Abe, M., Hendrickson, E., and Meek, K. (2016). Restoration of ATM Expression in DNA-PKcs-Deficient Cells Inhibits Signal End Joining. J Immunol 196, 3032-3042.

Nemoz, C., Ropars, V., Frit, P., Gontier, A., Drevet, P., Yu, J., Guerois, R., Pitois, A., Comte, A., Delteil, C., et al. (2018). XLF and APLF bind Ku80 at two remote sites to ensure DNA repair by non-homologous end joining. Nat Struct Mol Biol 25, 971-980.

Pettersen, E.F., Goddard, T.D., Huang, C.C., Couch, G.S., Greenblatt, D.M., Meng, E.C., and Ferrin, T.E. (2004). UCSF Chimera--a visualization system for exploratory research and analysis. J Comput Chem 25, 1605-1612.

Punjani, A., Rubinstein, J.L., Fleet, D.J., and Brubaker, M.A. (2017). cryoSPARC: algorithms for rapid unsupervised cryo-EM structure determination. Nat. Methods 14.

Richards, F.M., and Kundrot, C.E. (1988). Identification of structural motifs from protein coordinate data: secondary structure and first-level supersecondary structure. Proteins 3 , 71-84.

Shao, Z., Flynn, R.A., Crowe, J.L., Zhu, Y., Liang, J., Jiang, W., Aryan, F., Aoude, P., Bertozzi, C.R., Estes, V.M., et al. (2020). DNA-PKcs has KU-dependent function in rRNA processing and haematopoiesis. Nature 579, 291-296.

Sharif, H., Li, Y., Dong, Y., Dong, L., Wang, W.L., Mao, Y., and Wu, H. (2017). Cryo-EM structure of the DNA-PK holoenzyme. Proc Natl Acad Sci U S A 114, 7367-7372.

Sibanda, B.L., Chirgadze, D.Y., Ascher, D.B., and Blundell, T.L. (2017). DNA-PKcs structure suggests an allosteric mechanism modulating DNA double-strand break repair. Science 355, 520-524.

Swint-Kruse, L., and Brown, C.S. (2005). Resmap: automated representation of macromolecular interfaces as two-dimensional networks. Bioinformatics 21, 3327-3328. Walker, J.R., Corpina, R.A., and Goldberg, J. (2001). Structure of the Ku heterodimer bound to DNA and its implications for double-strand break repair. Nature 412, 607-614. West, R.B., Yaneva, M., and Lieber, M.R. (1998). Productive and nonproductive complexes of $\mathrm{Ku}$ and DNA-dependent protein kinase at DNA termini. Mol Cell Biol 18, 5908-5920.

Williams, D.R., Lee, K.J., Shi, J., Chen, D.J., and Stewart, P.L. (2008). Cryo-EM structure of the DNA-dependent protein kinase catalytic subunit at subnanometer resolution reveals alpha helices and insight into DNA binding. Structure 16, 468-477.

Williams, R.M., Yates, L.A., and Zhang, X. (2020). Structures and regulations of ATM and ATR, master kinases in genome integrity. Curr Opin Struct Biol 61, 98-105.

Yang, H., Jiang, X., Li, B., Yang, H.J., Miller, M., Yang, A., Dhar, A., and Pavletich, N.P. (2017). Mechanisms of mTORC1 activation by RHEB and inhibition by PRAS40. Nature 552, 368-373.

Yang, H., Rudge, D.G., Koos, J.D., Vaidialingam, B., Yang, H.J., and Pavletich, N.P. (2013). mTOR kinase structure, mechanism and regulation. Nature 497, 217-223. 
bioRxiv preprint doi: https://doi.org/10.1101/2020.10.19.346148; this version posted October 21, 2020. The copyright holder for this preprint

(which was not certified by peer review) is the author/funder, who has granted bioRxiv a license to display the preprint in perpetuity. It is made available under aCC-BY-NC-ND 4.0 International license.

Chen, et al., 2020

Yin, X., Liu, M., Tian, Y., Wang, J., and Xu, Y. (2017). Cryo-EM structure of human DNAPK holoenzyme. Cell Res 27, 1341-1350.

Zhang, K. (2016). Gctf: Real-time CTF determination and correction. J Struct Biol 193, 112.

Zheng, S.Q., Palovcak, E., Armache, J.P., Verba, K.A., Cheng, Y., and Agard, D.A. (2017). MotionCor2: anisotropic correction of beam-induced motion for improved cryo-electron microscopy. Nat Methods 14, 331-332. 
Chen, et al., 2020

\section{Figures}

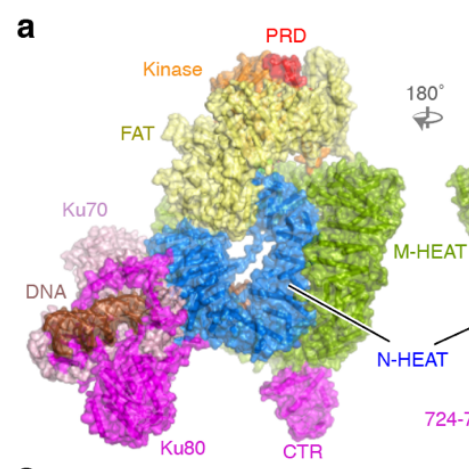

C
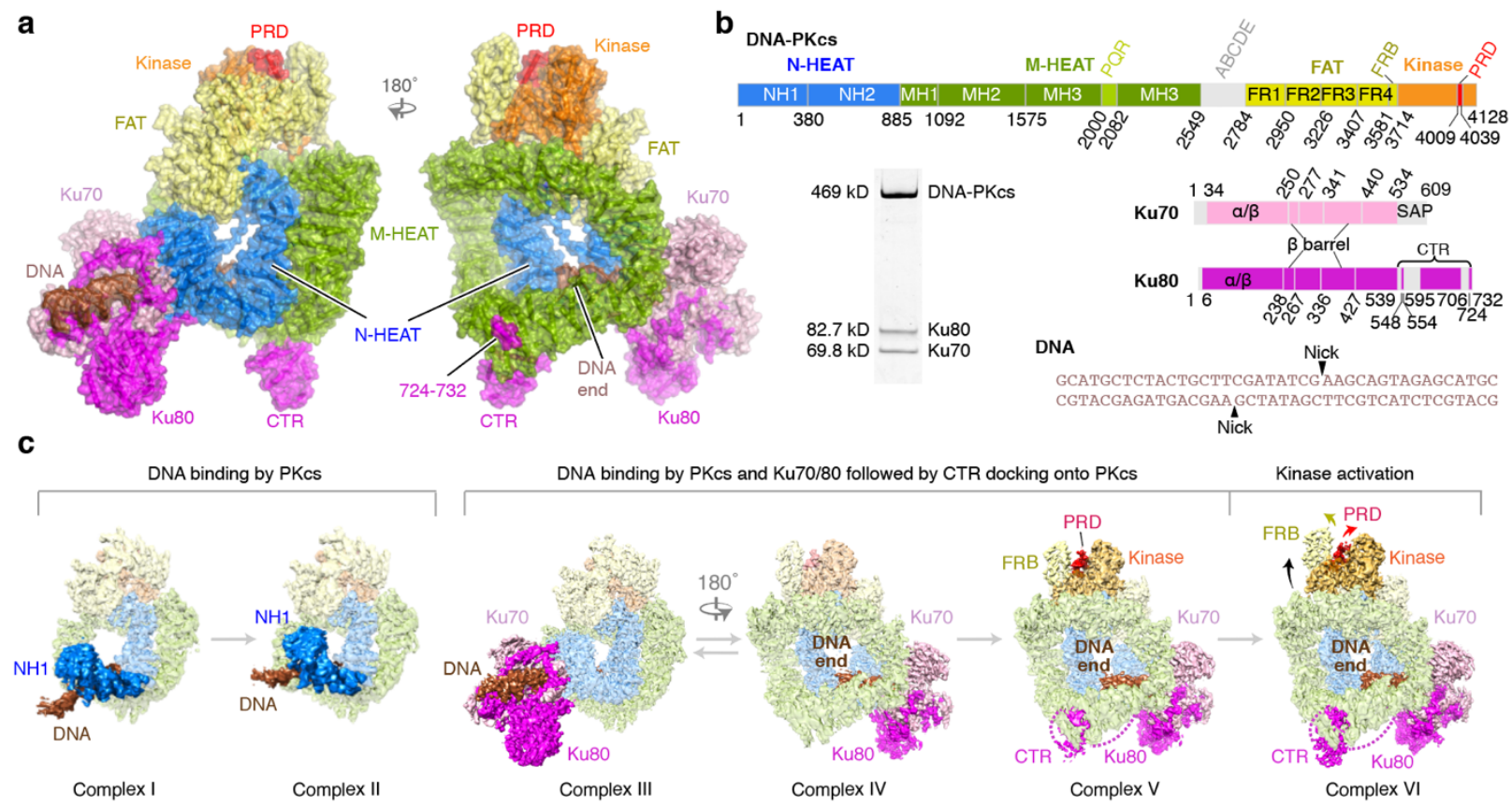

Kinase activation

Fig. 1. Structure characterization of DNA-PK complexed with DNA.

1a. Front and back views of the holo DNA-PK complex VI. Major parts are labeled and color coded.

1b. Diagrams of DNA-PKcs, Ku, and DNA sequences in the DNA-PK holo complexes. Quality of the protein sample is shown in the Coomassie-blue stained SDS gel.

1c. The cryoEM density maps of DNA-PK complexes I - VI and how they are related. Regions that differ among these complexes are highlighted in colors shown in 1a, while regions unchanged are shown in muted colors. Complexes I-III are shown in the back view as the DNA changes the most among them, and complexes IV-VI are shown in the front view to illustrate the changes in Ku80-CTR binding and the activation of the kinase. 
Chen, et al., 2020

a

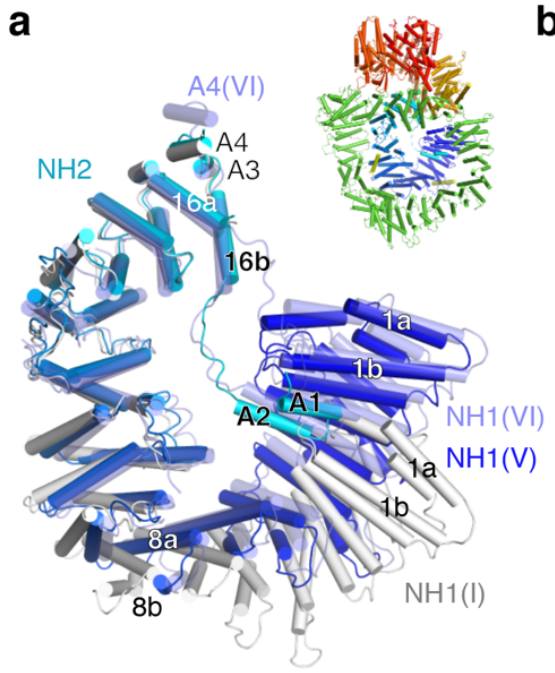

C

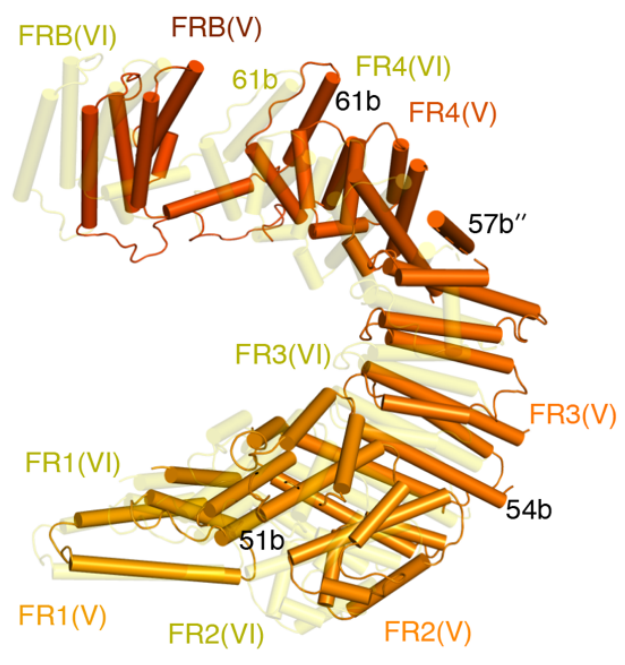

b

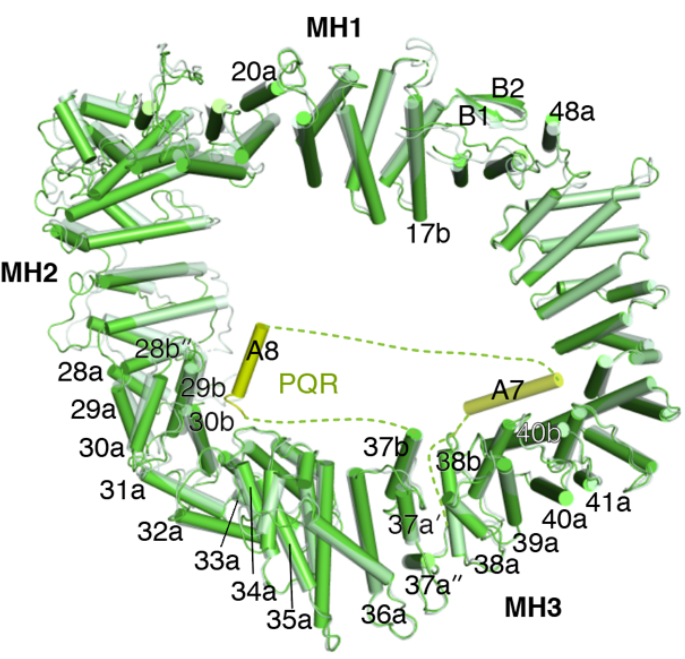

d

Inactive vs Activated Kinase

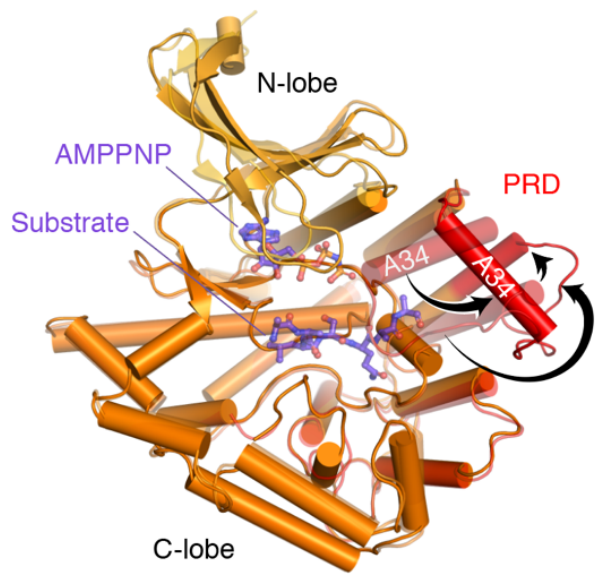

Fig. 2. The DNA-PKcs structure.

2a. The N-HEAT structures of Complex I (light grey), V (gradient colors of dark blue to cyan for residues 1 to 872), and VI (semi-transparent slate blue). The overall structure of DNA-PKcs is inserted as a reference.

2b. M-HEAT structures in complexes V (solid green) and VI (semi-transparent pale green) are superimposed. $\mathrm{MH} 2$ (at the 10 o'clock position) is most changed between the two. Helices A7 (V) and A8 (VI) of PQR are highlighted in lime color.

2c. FAT in complex V (solid orange to red) and VI (semi-transparent yellow) are superimposed at FR1. FAT is stretched between FR2 and FRB in complex VI (activated). 2d. Kinase domain in complex V (semi-transparent) and VI (solid orange) are superimposed by the $C$ lobe. AMPNPP and the substrate peptide (shown in semitransparent purple sticks) are borrowed from the SMG1 structure (PDB: 6Z3R) after superimposing the conserved kinase domain. PRD in complex VI (highlighted in red) is open (as indicated by black arrows). The closed PRD in complex $V$ would clash with the modeled substrate peptide. 
bioRxiv preprint doi: https://doi.org/10.1101/2020.10.19.346148; this version posted October 21, 2020. The copyright holder for this preprint (which was not certified by peer review) is the author/funder, who has granted bioRxiv a license to display the preprint in perpetuity. It is made available under aCC-BY-NC-ND 4.0 International license.

Chen, et al., 2020

a

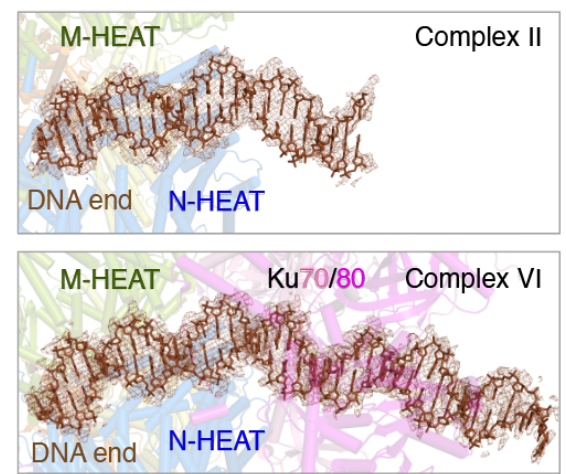

b

C
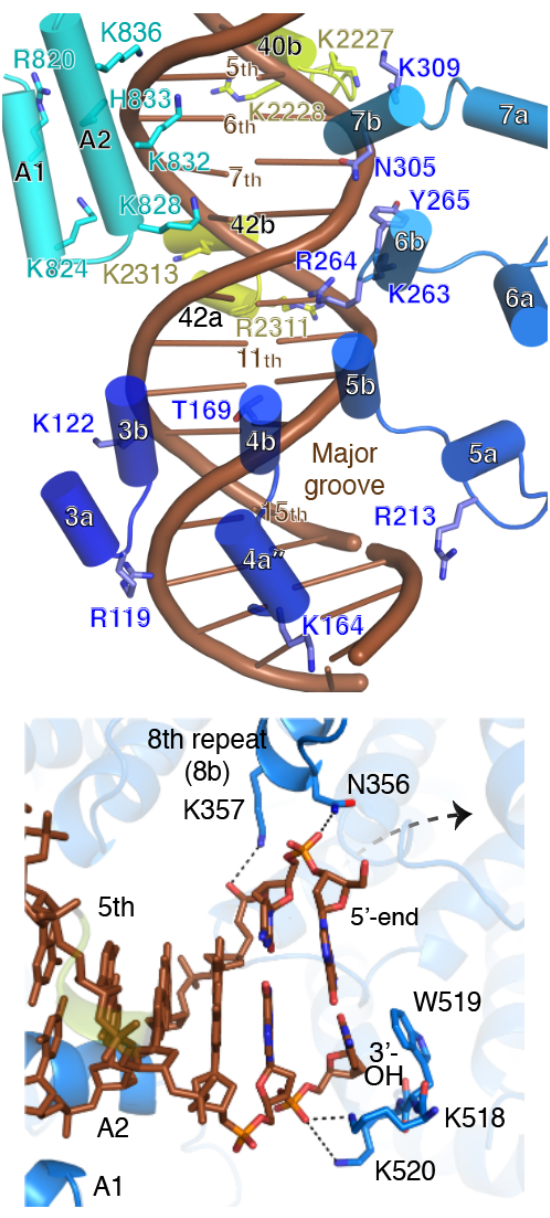

d

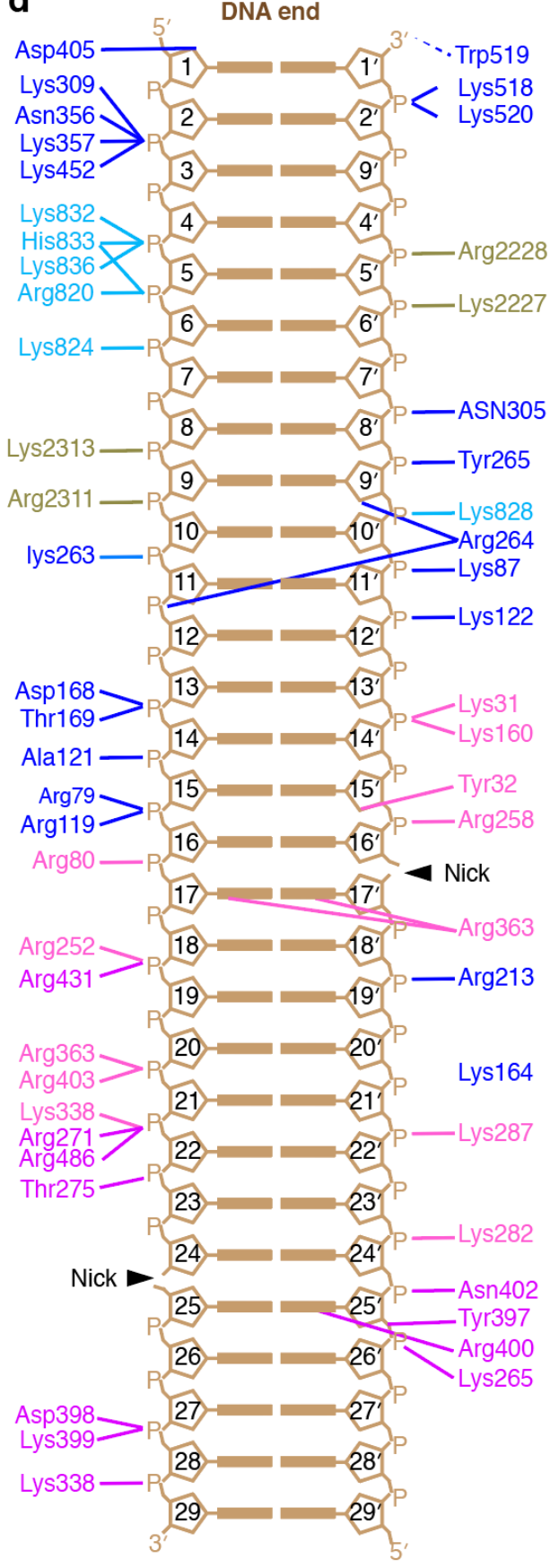

Fig. 3. DNA binding by DNA-PK

3a. Representative density maps of the DNA in complexes II and VI were contoured color at 5.5 and $5.0 \sigma$, respectively, in brown. Ku stabilizes the DNA in complexes III-VI.

3b. Interactions between the DNA and $\mathrm{NH} 1$, the extension of the $16^{\text {th }}$ helical repeat $(\mathrm{A} 1$, A2) and $\mathrm{MH} 3$ in complexes II-VI. Helices A1 and A2 are not docked onto DNA in complex I. Residues of DNA-PKcs at the interface with DNA are shown as sticks and labeled.

3c. In complexes III-VI, DNA-PKcs recognizes both DNA strands and caps the $3^{\prime}$ end specifically. Accommodation of a 5'-overhang is indicated by a dashed arrow.

3d. Diagram of the complete DNA interactions made by DNA-PKcs and Ku in complex VI. 
bioRxiv preprint doi: https://doi.org/10.1101/2020.10.19.346148; this version posted October 21, 2020. The copyright holder for this preprint (which was not certified by peer review) is the author/funder, who has granted bioRxiv a license to display the preprint in perpetuity. It is made available under aCC-BY-NC-ND 4.0 International license.

Chen, et al., 2020

a

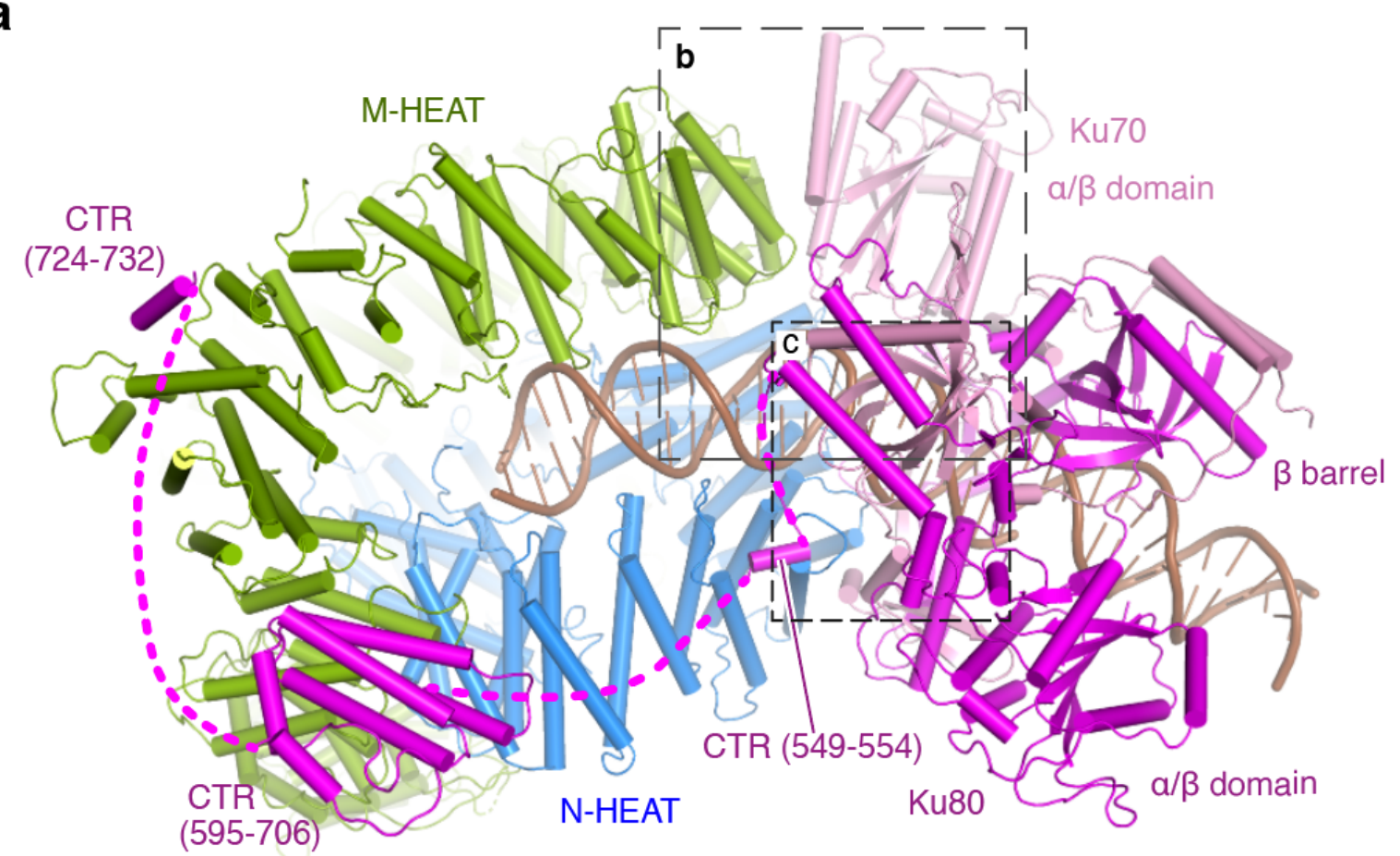

b

\section{C}
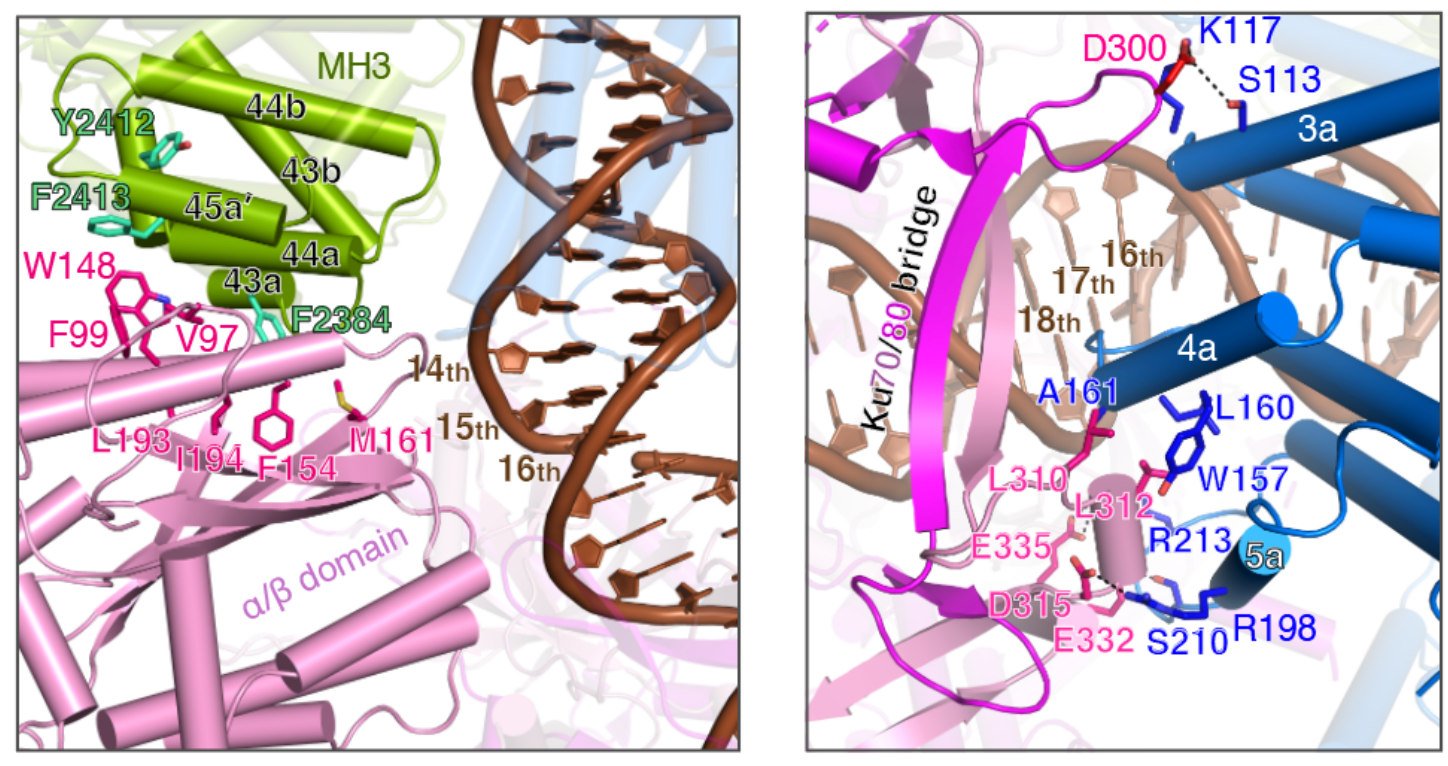

Fig. 4. Ku association with DNA and DNA-PKcs.

4a. A bottom view of the DNA-PK holo-complex (VI is used as an example).

4b. The $\alpha / \beta$ domain of Ku70 interacts with DNA and MH3 of DNA-PKcs. Hydrophobic residues forming the interface are shown as sticks and labeled.

4c. The bridges of Ku70/80, which binds the DNA major groove, interact with $\mathrm{NH} 1$ ( $3^{\text {rd }}$ to $5^{\text {th }}$ helical repeat), which interacts with the adjacent minor groove. The interacting residues are shown as sticks and labeled. 
a

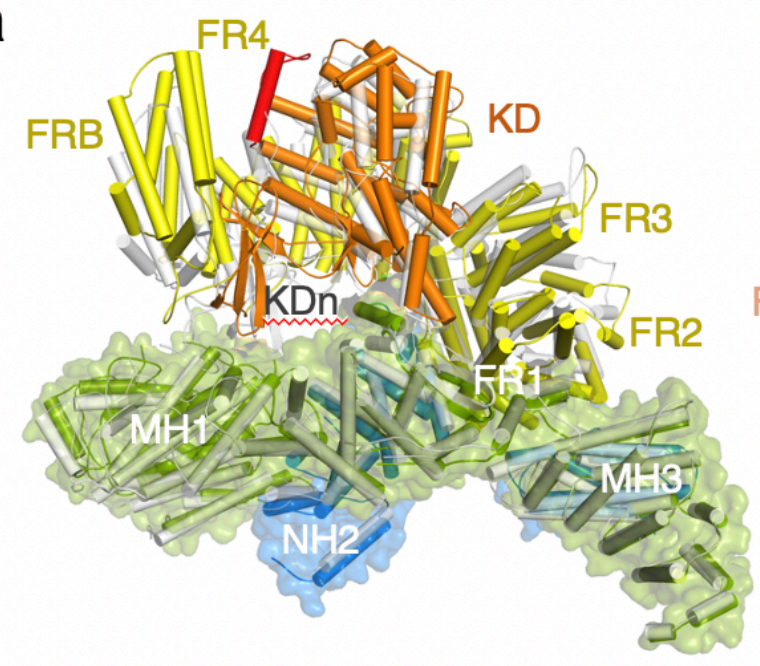

C

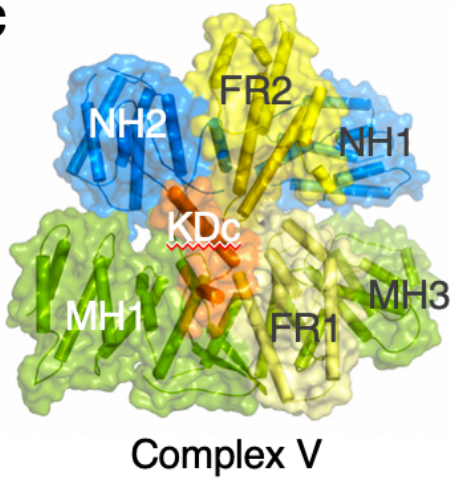

b
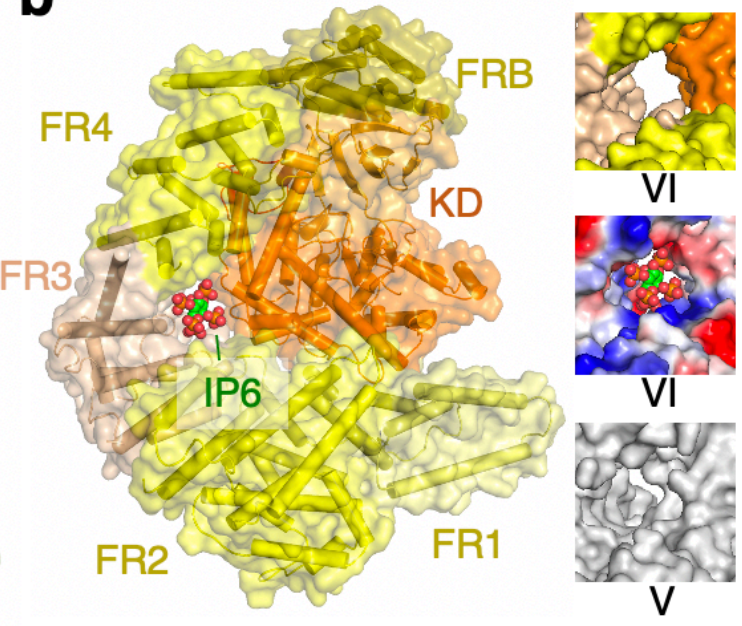

d
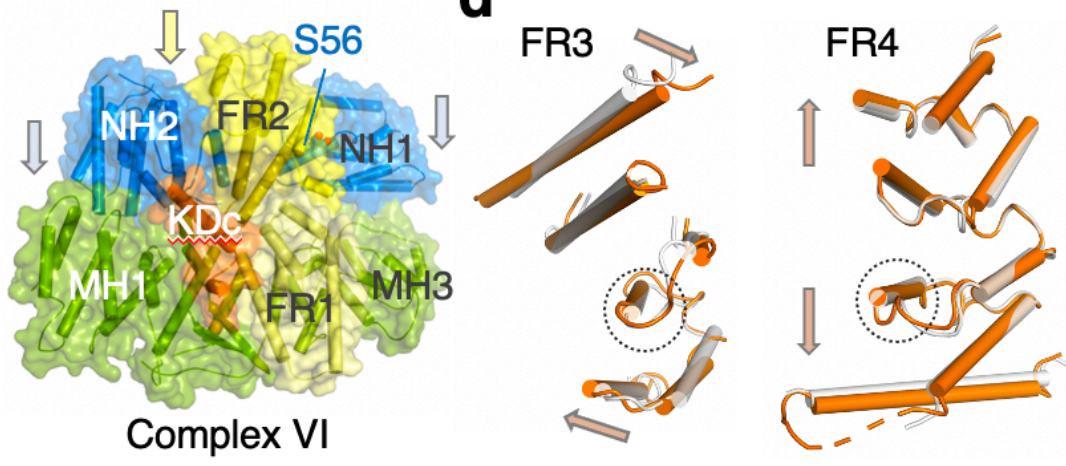

Fig. 5 Kinase activation.

5a. The FATKIN "head" in complex VI (multicolor) is raised relative to the body (covered molecular surface) compared with complex $\mathrm{V}$ (semi-transparent grey cartoon).

5b. In complex VI, a positively charged pocket potentially binding IP6 is formed between the kinase domain (KD) and FR3. The pocket doesn't exist in complex $V$ as shown in the insert.

5c. During transition from complex $\mathrm{V}$ and $\mathrm{VI}$, the N-HEAT ring with FR2 moves toward the M-HEAT ring (MH1, MH3 and FR1), where the kinase domain (aa 3882-3916) is docked. S56 contacts FR2 only in the activated state (complex VI).

5d. Comparison of FAT solenoid between complex V and VI. When one helix in FR3 or FR4 (in dashed circle) is superimposed, the surrounding helices twist (in FR3) or stretch (in FR4) in opposite directions as marked by arrowheads. 
bioRxiv preprint doi: https://doi.org/10.1101/2020.10.19.346148; this version posted October 21, 2020. The copyright holder for this preprint (which was not certified by peer review) is the author/funder, who has granted bioRxiv a license to display the preprint in perpetuity. It is made available under aCC-BY-NC-ND 4.0 International license.

\section{Supplemental Information}

\section{Tables S1-2}

2. Figures $\mathrm{S} 1-\mathrm{S} 5$

3. Movies 1-5 


\section{Table S1. Statistics of re-refinement of the DNA-PKcs crystal structure}

\begin{tabular}{|c|c|c|}
\hline & $\begin{array}{c}\text { Published apo-PKcs } \\
\text { PDB: 5LUQ }\end{array}$ & $\begin{array}{c}\text { Re-refined apo-PKcs } \\
\text { PDB: 7K17 }\end{array}$ \\
\hline \multicolumn{3}{|l|}{ Data collection } \\
\hline Space group & \multicolumn{2}{|c|}{ P21 } \\
\hline \multicolumn{3}{|l|}{ Cell dimensions } \\
\hline$a, b, c(\AA)$ & \multicolumn{2}{|c|}{169.1132 .6296 .6} \\
\hline$\alpha, \beta, \gamma\left({ }^{\circ}\right)$ & \multicolumn{2}{|c|}{$90,105.5,90$} \\
\hline Resolution $(\AA ̊)$ & \multicolumn{2}{|c|}{$49.9-4.3(4.41-4.3)$ * } \\
\hline$R_{\text {sym }}$ or $R_{\text {merge }}(\%)$ & \multicolumn{2}{|c|}{$16.0(93.6)$} \\
\hline$l / \sigma \mid$ & \multicolumn{2}{|c|}{$15.4(2.4)$} \\
\hline Completeness (\%) & \multicolumn{2}{|c|}{97.8} \\
\hline Redundancy & \multicolumn{2}{|c|}{$35.2(13.1)$} \\
\hline \multicolumn{3}{|l|}{ Refinement } \\
\hline Resolution $(\AA ̊)$ & 49.9-4.3 & $49.9-4.3$ \\
\hline No. reflections & 84530 & 84525 \\
\hline$R_{\text {work }} / R_{\text {free }}(\%)$ & $38.6 / 43.7$ & $28.6 / 33.5$ \\
\hline \multicolumn{3}{|l|}{ No. atoms } \\
\hline Protein & 59694 & 56895 \\
\hline Ligand/ion & 0 & 0 \\
\hline Water & 0 & 0 \\
\hline \multicolumn{3}{|l|}{$B$-factors } \\
\hline Protein & 253.0 & 217.0 \\
\hline \multicolumn{3}{|l|}{ R.m.s. deviations } \\
\hline Bond lengths $(\AA ̊)$ & 0.009 & 0.004 \\
\hline Bond angles $\left({ }^{\circ}\right)$ & 1.542 & 0.861 \\
\hline \multicolumn{3}{|l|}{ Validation } \\
\hline MolProbity score & 3.6 & 2.3 \\
\hline Clashscore & 54.7 & 14.1 \\
\hline Poor rotamers (\%) & 6.0 & 0.0 \\
\hline \multicolumn{3}{|l|}{ Ramachandran plot } \\
\hline Favored (\%) & 73.4 & 86.1 \\
\hline Allowed (\%) & 19.9 & 13.5 \\
\hline Disallowed (\%) & 6.7 & 0.4 \\
\hline
\end{tabular}

*The structure factor was downloaded from Protein Data Bank.

*Values in parentheses are for highest-resolution shell. 
bioRxiv preprint doi: https://doi.org/10.1101/2020.10.19.346148; this version posted October 21, 2020. The copyright holder for this preprint (which was not certified by peer review) is the author/funder, who has granted bioRxiv a license to display the preprint in perpetuity. It is made available under aCC-BY-NC-ND 4.0 International license.

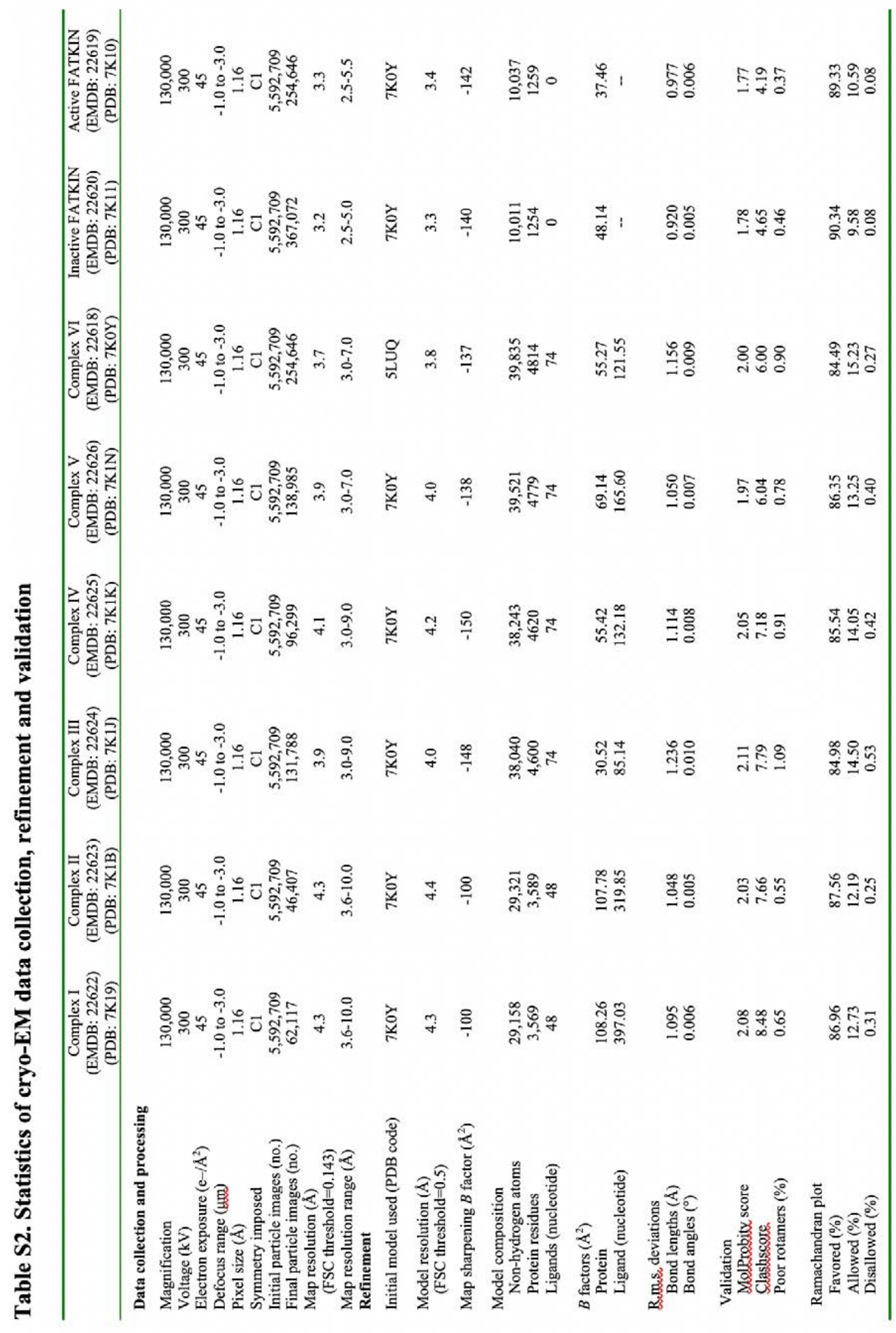


bioRxiv preprint doi: https://doi.org/10.1101/2020.10.19.346148; this version posted October 21, 2020. The copyright holder for this preprint (which was not certified by peer review) is the author/funder, who has granted bioRxiv a license to display the preprint in perpetuity. It is made available under aCC-BY-NC-ND 4.0 International license.
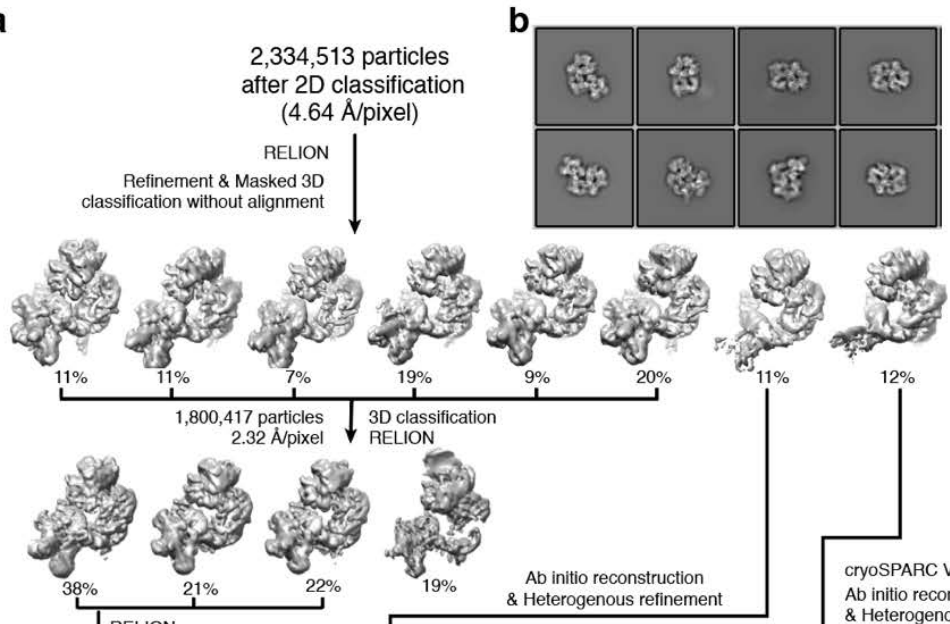

$19 \% \quad A b$ initio reconstruction Heterogenous refinement

RELION
Masked 3D classification without alignment

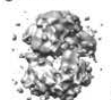

$2 \%$
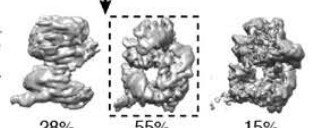

RELION $\begin{aligned} & \begin{array}{l}\text { Refinement \& } \\ \text { Masked 3D classific } \\ \text { without alignment }\end{array} \\ & \text { ing }\end{aligned}$

cryoSPARC V1
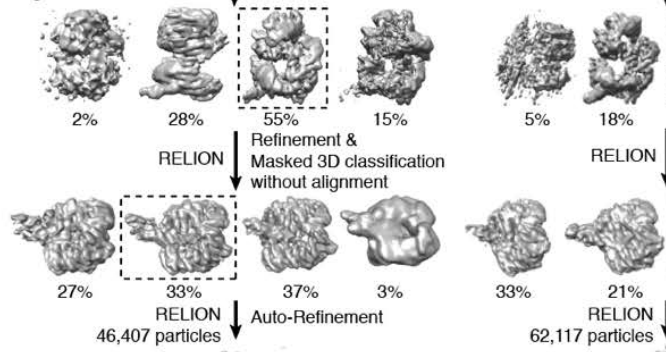

$5 \%$

$18 \% \quad 59 \% \quad 18 \%$

\begin{tabular}{l|l} 
RELION & $\begin{array}{l}\text { Refinement \& } \\
\text { Masked 3D classification }\end{array}$
\end{tabular}

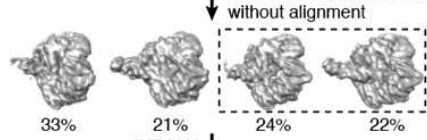

$33 \%$ RELION
62,117 particles
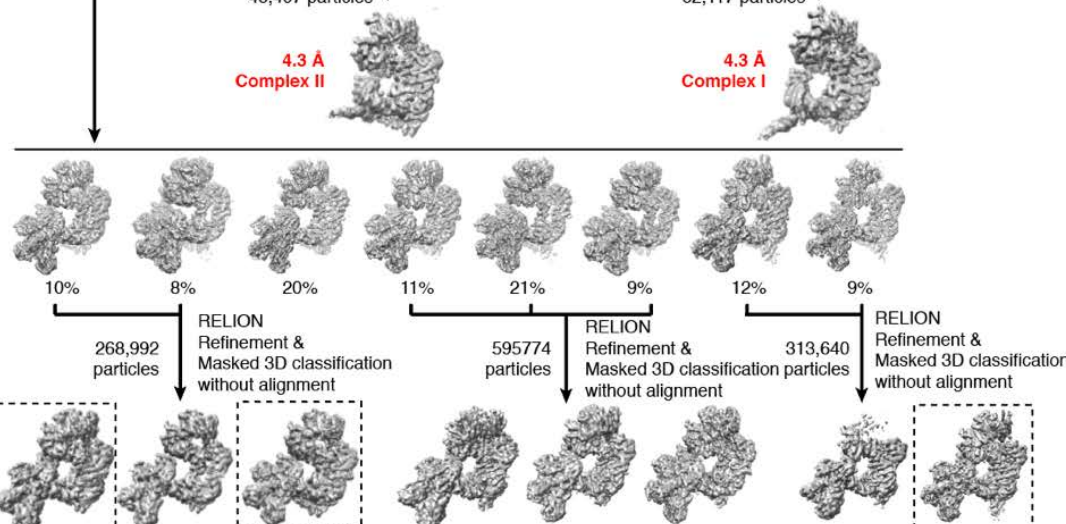

\section{$\checkmark$, wis}

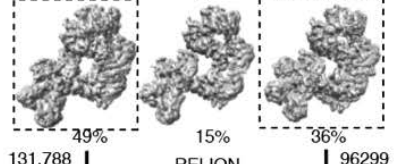

131,788
particles $\quad \begin{gathered}\text { RELION } \\ \text { Auto-Refinement }\end{gathered} \downarrow \begin{aligned} & 96299 \\ & \text { particles }\end{aligned}$
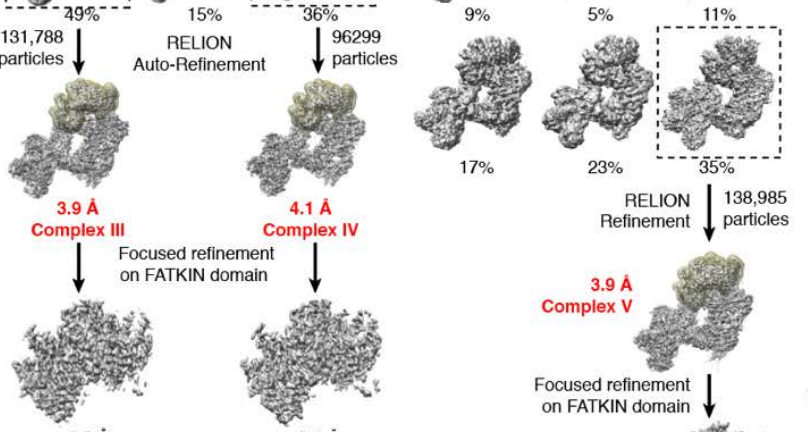

Focused refinement Focusedrement

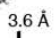

$3.6 \AA$

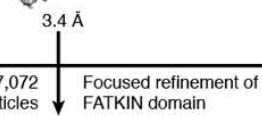

367,072
merged partic

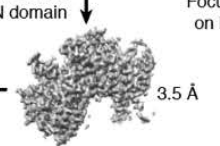

$3.2 \AA \AA$
Inactive FATKIN

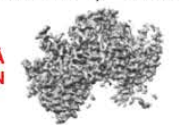

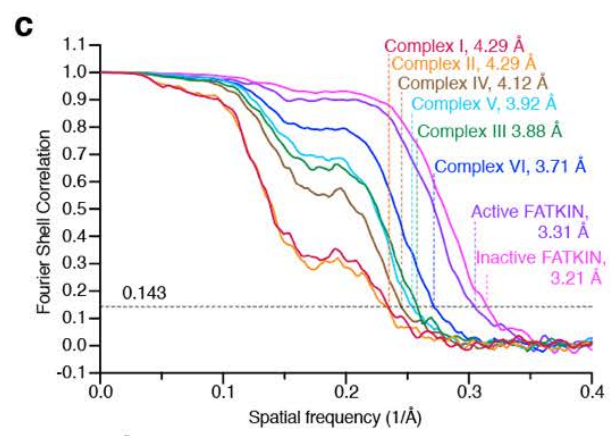

d
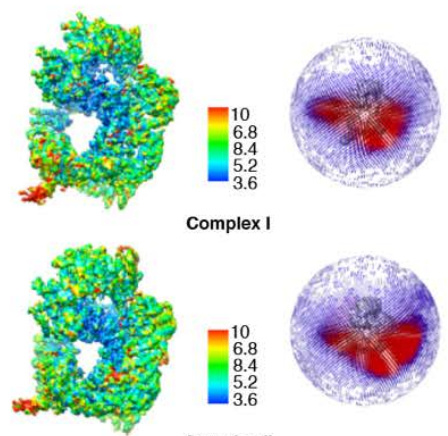

Complex II
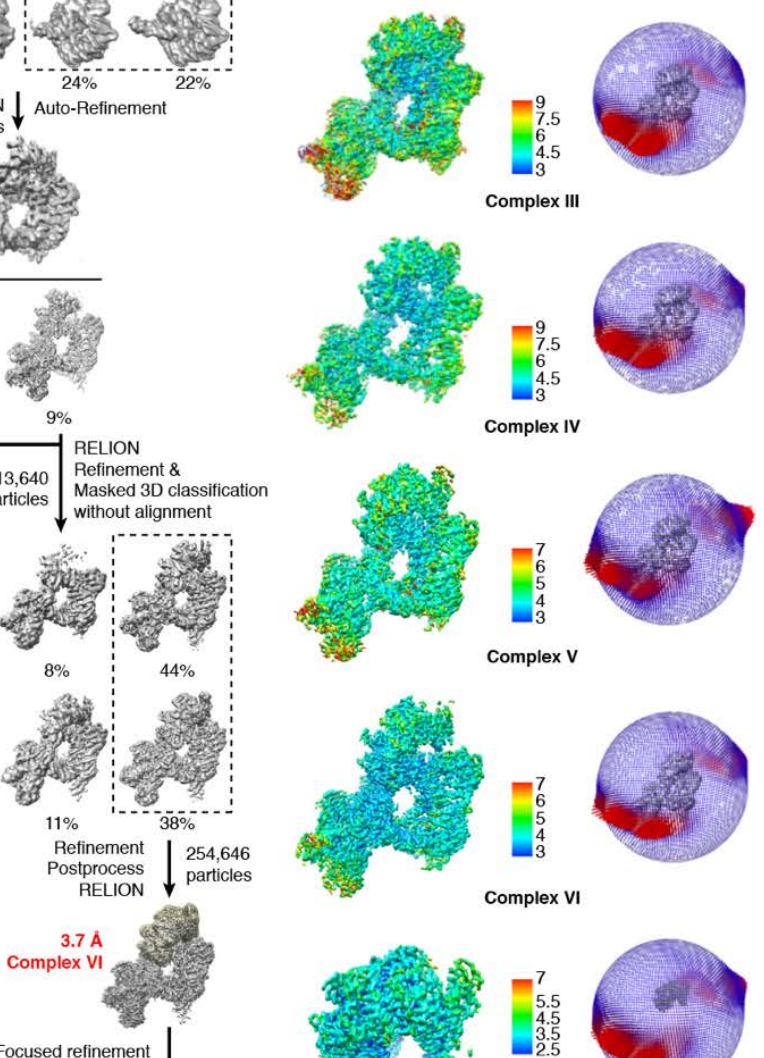

on FATKIN domain
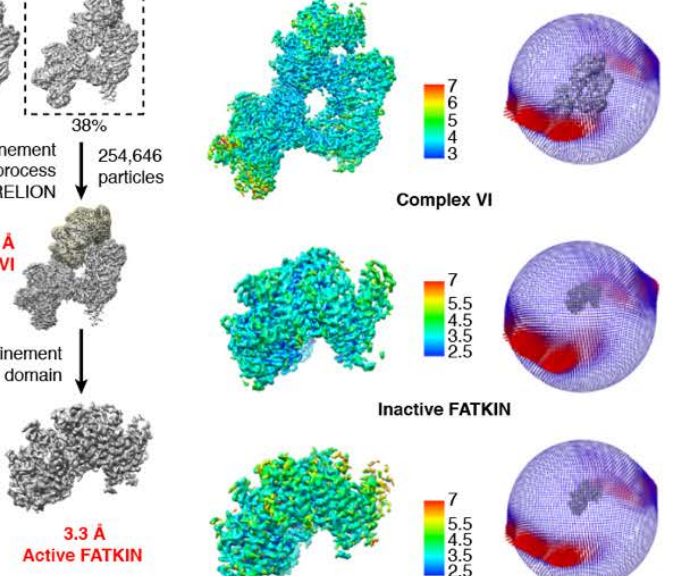

Complex VI
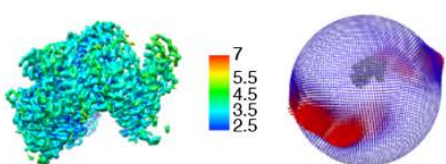

Inactive FATKIN
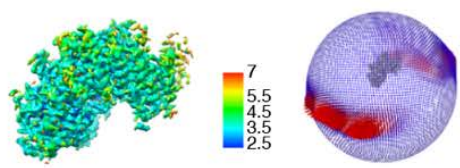

Active FATKIN 
Fig. S1. Structure determination of DNA-PK complexes by cryoEM.

S1a. After initial 2D and 3D classification, further 3D classification with and without alignment led to the final six DNA-PK complexes and two locally refined FATKIN structures.

S1b. Representative 2D classification results.

S1c. FSC analysis of the quality and map resolution of each complex structure.

S1d. For each complex, a surface presentation of its map, colored according to the local resolution estimated by ResMap and the scale bar on the side, and angular distributions of all particles used for the final three-dimensional reconstruction are shown. 
a

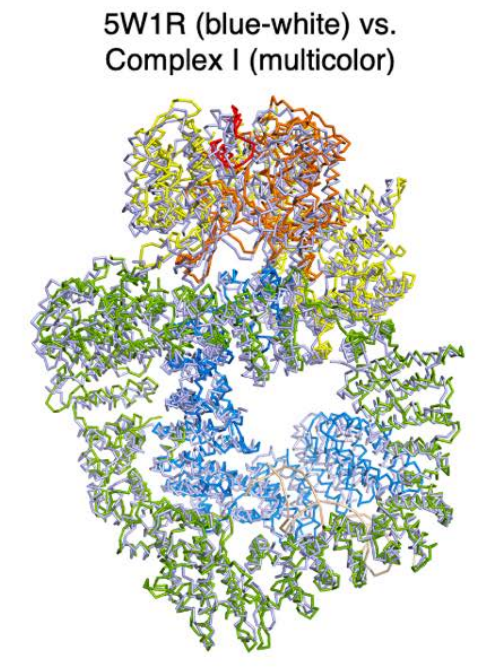

c

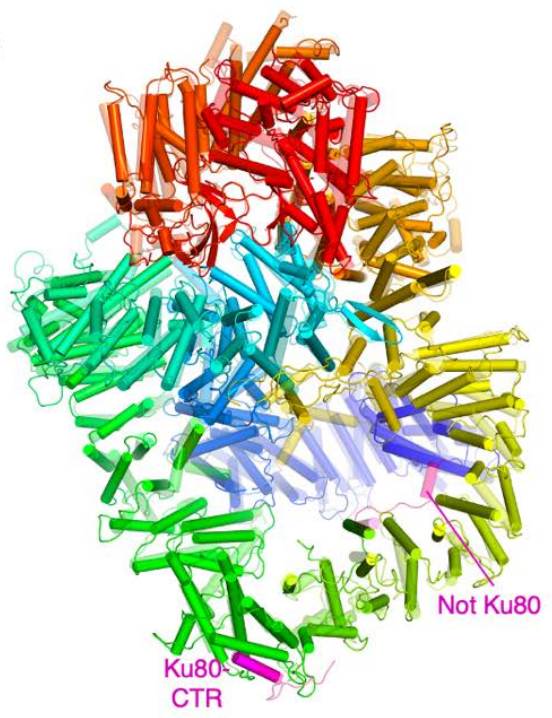

Re-refined PKcs (magenta Ku80)

vs. 5LUQ (semi-transparent) + hotpink Ku80 b 5Y3R (pale orange and purple "Ku80") vs Complex IV (multicolor)

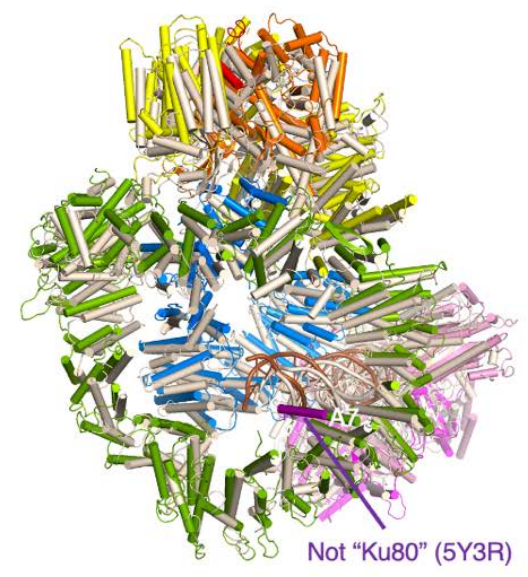

d

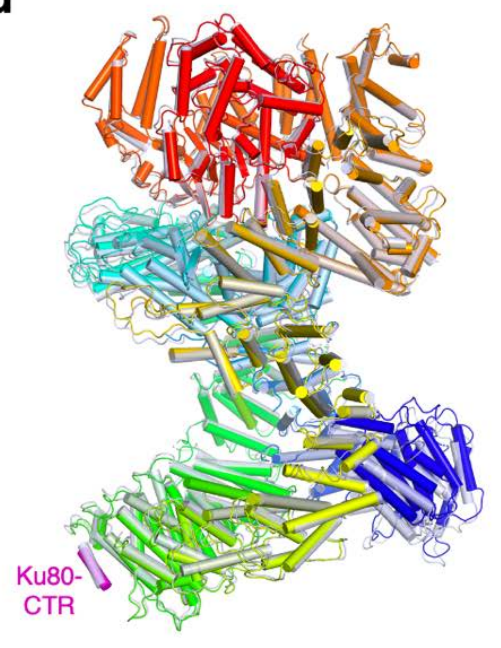

Re-refined PKcs Chain A (grey) vs Chain B (Rainbow + magenta Ku80)

Fig. S2. Structural comparison with previously published DNA-PK or DNA-PKcs.

S2a. Ribbon superposition of DNA-PKcs in complex I (multicolor) and $4.4 \AA$ cryoEM structure of DNA-PKcs alone (PDB: 5W1R, in blue-white).

S2b. Cartoon superposition of complex IV (multicolor as in Fig. 1a) with the previously reported 6.6 ̊̊ DNA-PK complex (PDB: 5Y3R, in wheat color). The purported Ku80 helices (dark purple) turned out to belong to DNA-PKcs.

S2c. Superposition of the re-refined (PDB: 7K17) (solid color) and the original crystal structure of DNA-PKcs (PDB: 5LUQ, semi-transparent) in rainbow colors (from blue N- to red C-terminus). The Ku80 CTR helices in the original model are colored pink. Only the very C-terminal one remains in the re-refined structure. The other two belong to DNAPKcs.

S2d. Two copies of DNA-PKcs in each asymmetric unit of the re-refined crystal structure are superimposed to show differences between them. One has rainbow colors and the other is colored in blue-grey. 


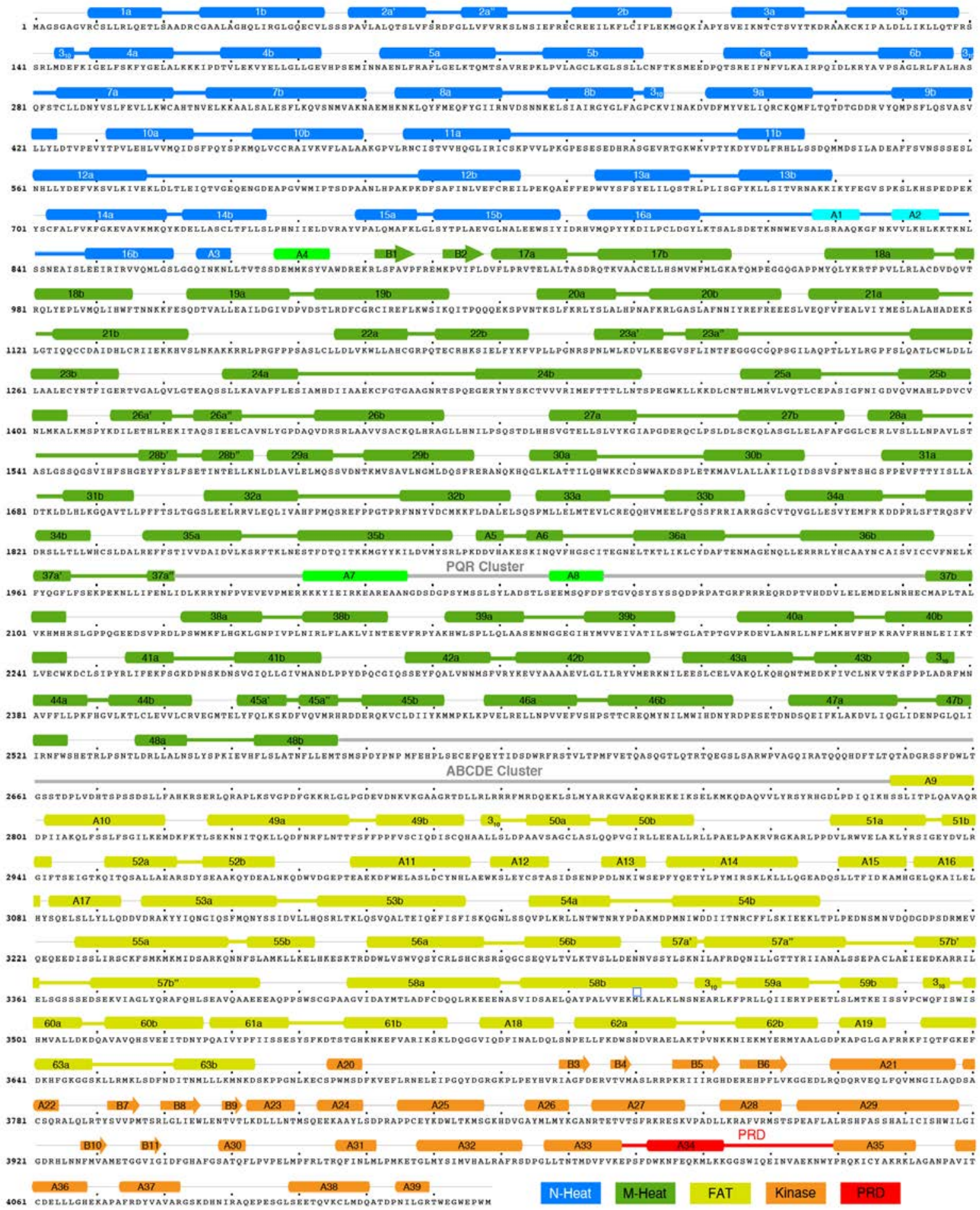

Fig. S3. The primary and secondary structures of DNA-PKcs.

Helical repeats are numbered from 1 to 63, and two helices in each repeat are labeled "a" and "b". Non-repeat $\alpha$ helices and $\beta$ are named sequentially as A1-A39 and B1-B11, respectively. Secondary structures are defined based on the $3.7 \AA$ complex VI structure. ABCDE and PQR clusters of DNA-PKcs autophosphorylation sites are marked. Colorcoding scheme for domains and associated secondary structures is shown at the bottom. 
Crystal (apo) vs. activated PKcs in Complex VI of DNA-PK

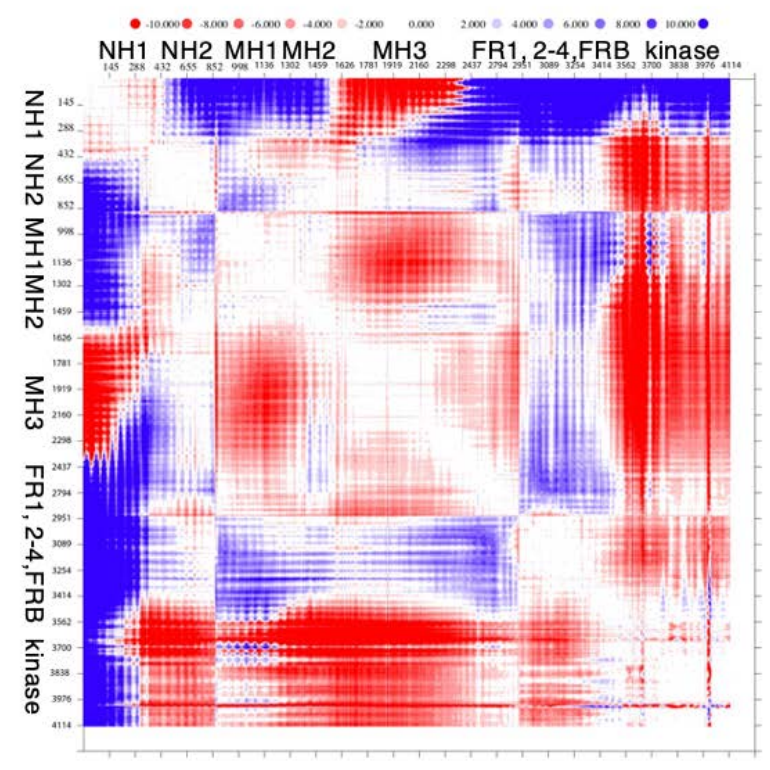

Inactive vs. activated PKcs in Complex V vs. VI of DNA-PK

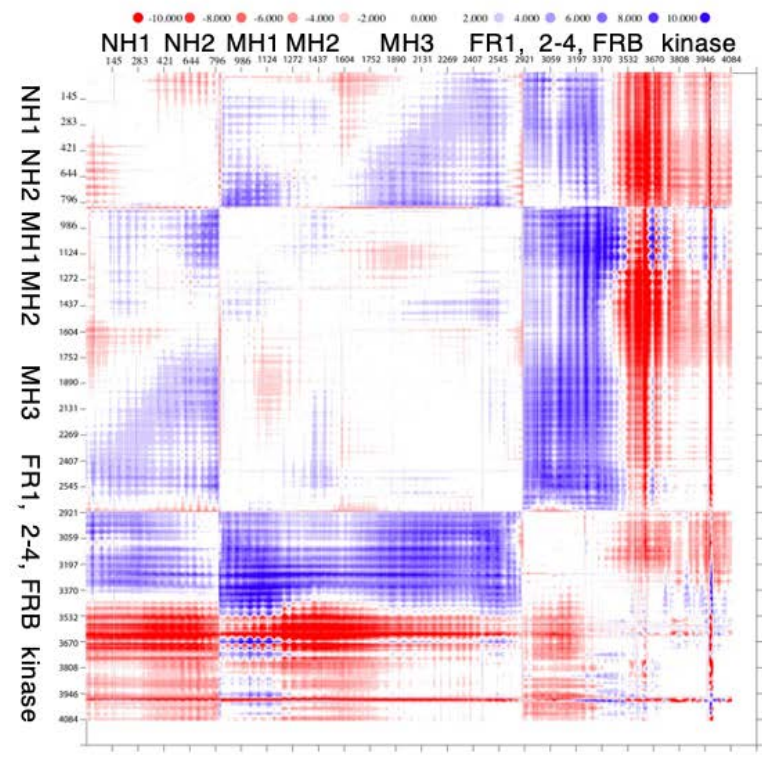

Fig. S4. DDMP analysis of domains in DNA-PKcs.

DDMP of DNA-PKcs between the re-refined crystal structure and complex VI (activated) (left) and of DNA-PKcs between complexes V and VI (right). Blue and red color indicate positive and negative distance changes. The maximal color scale is set to $10 \AA$. 


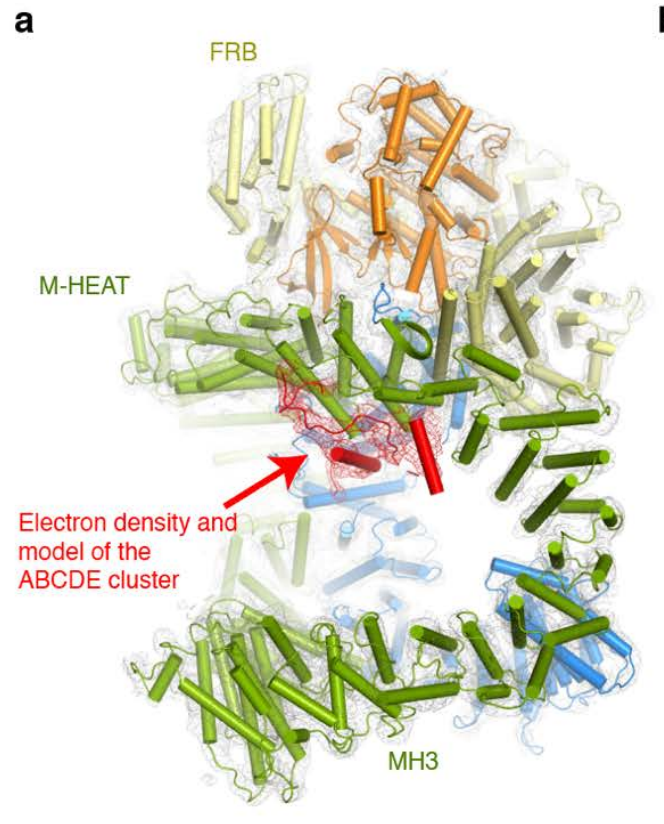

Apo PKcs crystal structure (PDB: 7K17) b

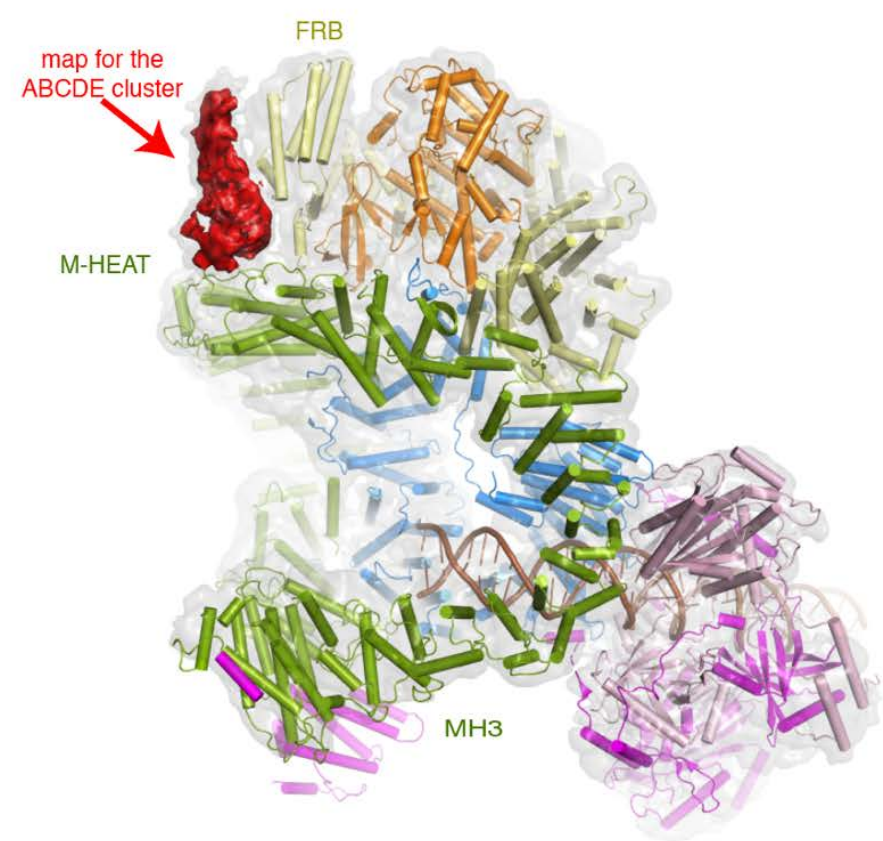

Complex V with cryoEM map

Fig. S5. Conformational changes of ABCDE cluster in apo DNA-PKcs and DNA-PK bound to DNA.

S5a. Cartoon model of the ABCDE cluster in chain A of re-refined crystal structure (PDB: $7 \mathrm{~K} 17)$ is superimposed with red electron density map (2Fo-Fc) contoured at $1 \sigma$.

S5b. The uninterpreted portion of unsharpened 3.74 $\AA$ cryoEM map in DNA-PK complex $\mathrm{V}$, which belongs to the ABCDE cluster, is contoured at $5 \sigma$ and shown in red. 